\title{
2. Die arbeitsrechtlichen Grundlagen
}

\section{SMAD-Befehl Nr. 65 und Kontrollratsbefehl Nr. 3}

Rechtliche Grundlagen der Arbeitskräftelenkung in der SBZ bildeten anfangs der SMAD-Befehl Nr. 65 vom 15. September 1945 sowie der Kontrollratsbefehl Nr. 3 vom 17. Januar 1946. Der SMAD-Befehl verpflichtete die ZVAS, die Registrierung der Bevölkerung vorzubereiten, Arbeitsbücher bzw. Registrierkarten einzuführen und monatlich einen Bericht über den Beschäftigten- und Arbeitslosenstand zu erstellen1. Den Arbeitsämtern „in den Städten und Bezirken“" wurde die Aufgabe übertragen, die Zählung „der gesamten beschäftigten und arbeitsfähigen arbeitslosen Stadtbevölkerung" vorzunehmen. Gleichzeitig erhielt die Arbeitsverwaltung eine herausgehobene Stellung, da nur sie die Arbeitsvermittlung durchführen konnte. Dagegen wurde Unternehmen, Organisationen, anderen Behörden aber auch Privatpersonen ausdrücklich untersagt, „Einstellungen ohne das Arbeitsamt vorzunehmen." Die Registrierung der von den Arbeitsämtern erfaßten Arbeitslosen hatte wöchentlich zu erfolgen. Darüber hinaus wurde die Kommunalverwaltung aufgefordert, jeden Monat der ZVAS einen ausführlichen Bericht über die Arbeitsmarktlage in ihrem Zuständigkeitsbereich vorzulegen. Personen, die sich der Registrierung widersetzten, drohte der Befehl mit dem Entzug der Lebensmittelkarten. Mitte Januar 1946 gab der Alliierte Kontrollrat einen Befehl heraus, der sich ebenfalls der Registrierung der arbeitsfähigen Bevölkerung und der Arbeitslosen sowie deren beruflicher Unterbringung widmete ${ }^{2}$. Im Gegensatz zum SMAD-Befehl enthielt der Befehl des Alliierten Kontrollrats viel präzisere Angaben, die für die SBZ von Relevanz waren und in späteren Befehlen der sowjetischen Besatzungsmacht bzw. in Gesetzen und Verordnungen der deutschen Verwaltungen oftmals wieder aufgegriffen wurden. So wurde etwa die Registrierung auf die arbeitsfähigen Männer im Alter von 14 bis 65 Jahren und auf die arbeitsfähigen Frauen im Alter von 15 bis 50 Jahren festgelegt ${ }^{3}$. Außerdem hatten sich die Arbeitslosen und -suchenden bei den Arbeitsämtern zur Registrierung zu melden. Erst gegen Vorlage eines Registrierungsausweises sollte dieser Personengruppe dann die Lebensmittelkarte ausgehändigt werden. Arbeitsunfähigkeit war von einer Ärztekommission zu überprüfen; in diesen Fällen konnte dann ein sogenanntes Arbeitsbefreiungszeugnis ausgestellt werden. Die Arbeitsplatzvermittlung erfolgte auch im Kontrollratsbefehl Nr. 3 über die Arbeitsämter. Neu war allerdings die Bestimmung, daß das Arbeitsamt „Personen durch Zwangsanordnungen in Arbeitsplätze“ einweisen konnte ${ }^{4}$. Der Alliierte Kontrollrat setzte auch Strafen fest: Bei Arbeitgebern konnte demzufolge eine Geldstrafe bis zu $10000 \mathrm{RM}$ und/oder eine Gefängnisstrafe bis zu einem Jahr verhängt werden. In „allen anderen Fällen“, d. h. bei Arbeitnehmern, lag die Geldstrafe bei bis zu 1000 RM und die Gefängnisstrafe bei bis zu drei Monaten ${ }^{5}$.

1 Arbeit und Sozialfürsorge 1 (1946), S. 3.

2 Kontrollratsbefchl Nr. 3 vom 17. 1. 1946, in: Amtsblatt des Kontrollrats in Deutschland, S. 131133.

3 Ebenda, S. 131.

4 Ebenda, S. 132.

5 Ebenda, S. 133. 
Die arbeitsrechtliche Lage war in der unmittelbaren Nachkriegszeit stellenweise unübersichtlich, da einzelne Gesetze und Bestimmungen aus der nationalsozialistischen Kriegswirtschaft rasch aufgehoben wurden ${ }^{6}$, während einige andere Verordnungen zunächst noch weiter Bestand hatten. Innerhalb der DVAS erstellte die Juristische Abteilung im Sommer 1946 eine Liste über nationalsozialistische Vorschriften, die den Arbeitseinsatz etwa im Rahmen des Vierjahrplanes regelten und die aufgehoben werden sollten7. Dieselbe Abteilung nannte im Spätsommer 1947 insgesamt 85 Verordnungen, Anordnungen, Durchführungsbestimmungen, Gesetze, Erlasse und Bekanntmachungen, die vom NS-Regime erlassen worden waren und nach 1945 außer Kraft gesetzt wurden ${ }^{8}$. Die Abteilung I $b$ bezweifelte allerdings, daß damit sämtliche Bestimmungen des nationalsozialistischen Arbeitsrechts aufgehoben seien?.

Da die Zentralverwaltungen in der Anfangszeit über wenig Einflußmöglichkeiten verfügten, fiel den Landes- bzw. Provinzialverwaltungen die Aufgabe zu, die Registrierung der Bevölkerung vorzunehmen. Hierbei spielten Berlin und Thüringen eine gewisse Vorreiterrolle. Gleichzeitig bereitete die ZVAS einige Verordnungen vor, welche die Arbeitskräftelenkung auf ein neues Fundament stellen sollten. Bereits am 28. September 1945, zwei Wochen nach Veröffentlichung des SMAD-Befehls Nr. 65, legte die ZVAS-Abteilung IV (Erfassung und Arbeitseinsatz der Bevölkerung) einen Verordnungsentwurf „über die Einstellung von Arbeitskräften in der [SBZ] " vor ${ }^{10}$. Dieser unterstrich nochmals die monopolartige Stellung des Arbeitsamtes bei der Einstellung von Arbeitskräften; darüber hinaus mußten offene Stellen "rechtzeitig“ gemeldet werden. Zu den Ausnahmeregelungen zählten nur Arbeitskräfte mit geringer Beschäftigung sowie Arbeitseinweisung bzw. -verpflichtung durch sowjetische Dienststellen. Diese blieben von Anfang an von der Kontrolle durch die Arbeitsverwaltung ausgenommen. Knapp zwei Wochen später präsentierte die Abteilung IV einen veränderten Entwurf, der zum einen die Aufgaben der Arbeitsämter aufzählte, zum anderen aber die $\mathrm{Zu}$ ständigkeit der Arbeitsverwaltung auf kommunaler Ebene leicht einschränkte. Arbeitsvermittlung, Berufsberatung und Lehrstellenvermittlung durften zwar von anderen Stellen nicht betrieben werden. Gleichzeitig sollte die ZVAS Ausnahmen gestatten können: Für einzelne Berufe konnte demnach eine „gewerbsmäßige oder nichtgewerbsmäßige Arbeitsvermittlung "zugelassen werden"1. Dies bedeutete die Zulassung von privater Arbeitsvermittlung und war letztlich der Ausnahmesituation der unmittelbaren Nachkriegszeit geschuldet. Die Arbeitsämter, die noch nicht vollständig errichtet worden waren, verfügten in dieser schwierigen Anfangszeit noch nicht über die nötigen Informationen, um den Arbeitsmarkt in seiner ganzen Breite analysieren sowie einen Arbeitskräftebedarf rechtzeitig erkennen und abdecken zu können. Insofern diente die Arbeitsvermittlung, die nicht von Arbeitsämtern, sondern beispielsweise von Subunternehmern durch-

\footnotetext{
6 Vgl. allgemein dazu Etzel, Die Aufhebung von nationalsozialistischen Gesetzen.

BAB, DQ 2/81, Bl. 71-73.

BAB, DQ 2/111, Bl. 63-70, Juristische Abt. am 25. 9. 1947 an Abt. I b.

Ebenda, Bl. 74, Aktenvermerk der Abt. I b vom 4. 11. 1947.

$10 \mathrm{BAB}, \mathrm{DQ} 2 / 2064$.

1 Ebenda, Entwurf der Abt. IV vom 9. 10. 1945, $\$ 5$, Abs. 1.
} 
geführt wurde, der Entlastung auf dem Arbeitsmarkt bzw. auf den Teilarbeitsmärkten.

Frühzeitig wurde erkennbar, daß der Befehl der sowjetischen Besatzungsmacht nicht ohne weiteres umzusetzen war. So berichteten einige thüringische Arbeitsämter, daß staatliche Behörden nach wie vor Einstellungen ohne Einschaltung des Arbeitsamtes vornehmen würden ${ }^{12}$. Das Landesamt für Arbeit bat daraufhin Präsident Rudolf Paul, eine entsprechende Weisung an alle nachgeordneten Behörden des Landes zu erteilen. Es dürfe nicht der Eindruck entstehen, daß „zwar die privaten Betriebe sich nach den Weisungen der staatlichen Stellen richten müssen, die staatlichen Stellen selbst aber die erlassenen Anordnungen nicht beachten "13. Im Zusammenhang mit dem Befehl Nr. 3 des Alliierten Kontrollrates erließ das thüringische Landesamt für Arbeit erst am 6. März 1946 eine Durchführungsbestimmung, die nochmals unterstrich, daß Einstellungen nur mit Zustimmung des zuständigen Arbeitsamtes vorzunehmen waren ${ }^{14}$. In einigen anderen Punkten ging die Durchführungsbestimmung noch etwas weiter: Für die Registrierung der Arbeitskräfte wurde eine Frist genannt (20. März). Diejenigen, die bis zu diesem Zeitpunkt nicht im Besitz der Registrier- oder Meldekarte waren, sollten demzufolge vom Bezug der Lebensmittelkarten ausgeschlossen werden.

Die Arbeitsvermittlung wurde rasch mit der immer drängenderen Aufgabe der Bereitstellung von Arbeitskräften für zentrale Wirtschaftsbranchen verknüpft. Hintergrund dafür waren die sowjetischen Reparationsforderungen und der wachsende Arbeitskräftebedarf von seiten der sowjetischen Besatzungsmacht. In diesem Zusammenhang muß die Ausarbeitung einer Richtlinie durch die Juristische Abteilung der ZVAS gesehen werden. Diese verpflichtete die Betriebsräte, Betriebsobleute und Vertrauensleute des FDGB sowie die Betriebsleiter dazu, „in vertrauensvoller, kameradschaftlicher Einflußnahme die Arbeitspflichtigen zur Durchführung der ihnen obliegenden Pflichten anzuhalten"15. Das Arbeitsamt konnte sogar die genannten Funktionsträger zur Verantwortung ziehen. Der Entwurf betonte zugleich die Durchführung der statistischen Erfassung aller erwerbstätigen Personen. Dazu erließ die ZVAS kurz nach dem Erscheinen des Kontrollratsbefehls Nr. 3 eine Richtlinie ${ }^{16}$.

Sowohl der SMAD-Befehl Nr. 65 als auch der Kontrollratsbefehl Nr. 3 ließen etliche Detailfragen offen, die die Arbeitsverwaltung sukzessive selbst zu klären hatte. Dabei erwies sich das in der Anfangszeit noch weitgehend ungeklärte Verhältnis zwischen Zentral- und Landesverwaltungen durchaus als Hindernis. Oftmals waren es sogar die jeweiligen Landesämter, die sich mit einer Problemstellung an die Berliner Zentralverwaltung wandten. So warf etwa der Präsident des Landesarbeitsamtes Sachsen am 15. Mai 1946 die Frage nach der Zulässigkeit von Kündigungen auf ${ }^{17}$. Die arbeitsrechtlich gesehen offene Lage ergab sich daraus, daß der Befehl des Alliierten Kontrollrats eine Kündigung indirekt von der Zu-

12 ThHStA, Land Thüringen, Büro des Ministerpräsidenten, Bd. 1678, Thüringisches Landesamt für Arbeit am 4. 10. 1945 an den Präsidenten des Landes.

13 Ebenda, S. If.

14 ThHStA, Land Thüringen, Ministerium für Wirtschaft und Arbeit, Bd. 3704, Bl. 79.

$15 \mathrm{BAB}, \mathrm{DQ} 2 / 1754$, Richtlinienentwurf vom 1.2.1946.

16 Arbeit und Sozialfürsorge 1 (1946), S. 9 f.

17 BAB, DQ 2/1767, Präsident des Landesarbeitsamtes Sachsen am 15. 5. 1946 an ZVAS. 
stimmung des Arbeitsamtes abhängig machte. Dagegen sprachen allerdings die bestehenden tariflichen Bestimmungen. Das sächsische Landesarbeitsamt drängte auf eine Lösung und verwies darauf, daß in ihrem Zuständigkeitsbereich „viele Betriebe erwerbsbeschränkte Personen entlassen [würden], um volleinsatzfähige Kräfte, die jetzt mit dem Auslaufen von Demontagen in größerer Zahl verfügbar werden, einzustellen" ${ }^{18}$. Die Juristische Abteilung der ZVAS bestätigte die Einschätzung, daß der Kontrollratsbefehl Nr. 3 ausdrückliche Bestimmungen über die Zulässigkeit von Kündigungen nicht enthielt ${ }^{19}$. Nach Ansicht der ZVAS-Abteilung konnten jedoch die Unternehmer keine Entlassungen mehr alleine vornehmen. Bei der Auslegung des Befehls müsse vielmehr die allgemeine Arbeitsmarktlage und die Notwendigkeit zur Steuerung durch die Arbeitsämter berücksichtigt werden. Daher sollte „in Zweifelsfällen [...] den Grundsätzen einer straffen Arbeitslenkung Rechnung getragen" werden. Eine Einschaltung des Arbeitsamtes sei - so die Juristische Abteilung - nicht erforderlich bei einer Lösung des Arbeitsverhältnisses im gegenseitigen Einverständnis. Ansonsten sei die Mitwirkung des Arbeitsamtes „unter allen Umständen zu bejahen“. Etwas anders sah dies offensichtlich die Abteilung II b der ZVAS, die zu dem Schluß gelangte, daß „die Kündigung als solche ohne Genehmigung des Arbeitsamtes formell gesehen zulässig ist" ${ }^{20}$. Das Arbeitsamt könne somit die Lösung eines Arbeitsverhältnisses nur zur Kenntnis nehmen. In der Folgezeit entwickelte sich eine rege Debatte über die Frage, inwieweit das Arbeitsamt einer Kündigung zustimmen oder sie nur registrieren durfte, die nicht so rasch entschieden werden konnte.

Vergleichsweise unstrittig war dagegen die Zustimmungspflicht der Arbeitsämter bei einem Arbeitsplatzwechsel, zumal auch hier die Bestimmung des Kontrollratsbefehls Nr. 3 eindeutig war. Die ZVAS gab am 12. Juni 1946 ein Rundschreiben an die Landes- bzw. Provinzialämter heraus und unterstrich nochmals die Einschaltung des jeweiligen Arbeitsamtes ${ }^{21}$. Das Provinzialamt für Arbeit und Sozialfürsorge von Sachsen-Anhalt ging sogar noch einen Schritt weiter und wies seinerseits die ihr unterstehende Arbeitsverwaltung an, auch in dem Fall auf der Zustimmungspflicht zu bestehen, wenn ein Arbeitsvertrag im beiderseitigen Einverständnis aufgelöst wurde ${ }^{22}$. Das bedeutete, daß ein Arbeitsverhältnis ohne vorherige Zustimmung des Arbeitsamtes generell nicht rechtswirksam gekündigt werden konnte. Der Leiter des Provinzialamtes begründete dies gegenüber der ZVAS mit dem Hinweis auf die "hiesige sehr angespannte Arbeitseinsatzlage“. Zwischen einzelnen Abteilungen der DVAS herrschten jedoch in diesem Punkt unterschiedliche Auffassungen über die arbeits- und sozialrechtlichen Konsequenzen. So erschien im amtlichen Organ der DVAS am 1. November 1946 ein Beitrag über „Entlassungsschutz und Arbeitsamt“, in welcher der Autor Günther Müller die Schlußfolgerung zog, daß „die Zustimmungserklärung des Arbeitsamtes auf eine Kündigung oder Entlassung ohne Einfluß auf die tatsächlichen Be-

18 Ebenda, S. 2.

19 BAB, DQ 2/1767, ZVAS am 18. 5. 1946 an das Landesarbeitsamt Sachsen.

$20 \mathrm{BAB}, \mathrm{DQ} 2 / 729$, Vermerk vom 20.5. 1946.

$21 \mathrm{BAB}, \mathrm{DQ} 2 / 63$, Rundschreiben Nr. 78 vom 12.6. 1946.

22 BAB, DQ 2/1767, Provinzialamt für Arbeit und Sozialfürsorge von Sachsen-Anhalt am 25. 6. 1946 an die ZVAS. 


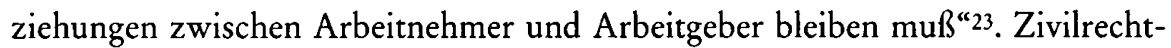
lich relevant blieben lediglich die Rechtsfolgen einer Schadensersatzpflicht für den Fall der Nichtbeachtung. Doch auch dies wurde im Beitrag in Zweifel gezogen, da ansonsten die zivilrechtliche Bestimmung den Charakter eines Kündigungsschutzes gewinnen würde, der bereits hinreichend festgelegt worden sei. Gustav Schaum von der Abteilung III a teilte diese Rechtsauffassung nicht und bat Vizepräsident Herm, eine gemeinsame Aussprache herbeizuführen, „damit nicht nach außen der Eindruck erweckt wird, daß jede Abteilung unseres Hauses anders entscheidet" 24 . Dagegen unterstützte der Leiter der Juristischen Abteilung Helm den in dem Artikel geäußerten Standpunkt und zeigte sich über die Reaktion Schaums verwundert, der angeblich zuvor auf einer Konferenz in Meißen seine Zustimmung gegeben hatte ${ }^{25}$. Eine gemeinsame Aussprache, die wenige Tage später stattfand, erbrachte Übereinstimmung darüber, daß Entscheidungen der Arbeitsämter „auch entsprechende Auswirkungen auf die Rechtsbeziehungen der Vertragsparteien eines Einzelarbeitsvertrages haben "26. Damit hatte sich interessanterweise die Juristische Abteilung nicht durchsetzen können. Das Ergebnis muß allerdings auch vor dem Hintergrund des wachsenden Arbeitskräftebedarfs und der Fluktuation von Arbeitskräften gesehen werden, der die Arbeitsverwaltung offenbar etwas ratlos gegenüberstand.

Auch die Bestimmung des Kontrollratsbefehls Nr.3, wonach Entlassungen durch den Arbeitgeber dem zuständigen Arbeitsamt mitzuteilen waren, schien aus Sicht der DVAS klärungsbedürftig zu sein. Abteilungsleiter Heinrich Kreil sprach sich auch in diesem Fall für eine Zustimmungspflicht des Arbeitsamtes aus und schlug eine entsprechende Anweisung vor ${ }^{27}$. Danach sollte jeder Arbeitsplatzwechsel zustimmungspflichtig sein. Die Zustimmungspflicht hatte sich auf alle Arbeitskräfte, die in einem Arbeits- oder Ausbildungsverhältnis standen, zu beziehen. Auch eine Kündigung im beiderseitigen Einverständnis war - so der Vorschlag Kreils - erst dann rechtsgültig, wenn das Arbeitsamt keinen Einspruch einlegte. In Fällen, bei denen sich Arbeitgeber und Arbeitnehmer nicht einigen konnten, fiel dem Arbeitsamt ebenfalls die alleinige Entscheidung zu. Kreil schlug deshalb im Januar 1947 dem DVAS-Präsidenten die Herausgabe einer gesonderten Verordnung vor, die den Arbeitsplatzwechsel gesetzlich regeln sollte ${ }^{28}$. Im einzelnen sollten die Arbeitgeber verpflichtet werden, Massenentlassungen mindestens eine Woche vorher beim Arbeitsamt anzuzeigen. Darüber hinaus hatte das Arbeitsamt seine Zustimmung zu jeder Auflösung eines Arbeitsvertrages zu geben. Einer Zustimmung - so Kreil weiter - bedurfte es nicht bei Betriebsschließungen sowie bei einer probeweisen Anstellung bzw. Aushilfsanstellung. Von zentraler Bedeutung war aber der Vorschlag, nach der das Arbeitsamt „nicht über die rechtliche Zulässigkeit der Kündigung, sondern allein auf Grund arbeits-

23 Arbeit und Sozialfürsorge 1 (1946), S. 369 f., hier S. 370.

24 BAB, DQ 2/262, Bl. 7, Schaum am 28. 1. 1947 an Herm.

25 Ebenda, Bl. 8, Helm am 30.1. 1947 an Vizepräsident Herm.

26 Ebenda, Bl. 9, Niederschrift der Abt. III a (Schaum) vom 6. 2. 1947.

$27 \mathrm{BAB}, \mathrm{DQ} 2 / 63$, Kreil am 13.11. 1946 an Gustav Schaum.

28 $\mathrm{BAB}, \mathrm{DQ}$ 2/1767, Kreil am 31. 1. 1947 an Brack. 
marktbedingter Erwägungen" zu entscheiden hatte29. Damit öffnete sich der Arbeitsverwaltung ein breiter Interpretationsspielraum.

Als weiterer Konfliktfall erwies sich das im Kontrollratsbefehl Nr. 3 verbriefte Recht der Arbeitsämter, Arbeitsplatzeinweisungen vornehmen zu können. Im Befehl des Alliierten Kontrollrates rangierte dieses Zwangsmittel allerdings unter dem Kapitel, das sich mit der beruflichen Unterbringung von Arbeitslosen befaßte. Deshalb drehte sich auch die bald einsetzende Diskussion um die Frage, ob die Zwangseinweisung nur für Arbeitslose oder generell für alle Erwerbstätigen zu gelten hatte. Die DVAS-Abteilung I b legte am 25. März 1947 einen Anweisungsentwurf vor, der die sogenannte Lösung von Arbeitsverhältnissen regeln sollte, und vertrat in dem Zusammenhang einen gemäßigten Kurs: Es müsse bei der Durchführung vermieden werden, daß „die Arbeitnehmerschaft diesen Befehl als eine Zwangseinrichtung gemäß der üblen Praxis des vergangenen Regimes empfindet" 30 . Daher solle vom Recht der Arbeitseinweisung - so die Abteilung $\mathrm{I} b$ in ihrer Stellungnahme - nur in "dringenden Fällen" Gebrauch gemacht werden. Dazu gehörten Befehle der sowjetischen Besatzungsmacht, der Katastrophendienst, die Versorgung der Bevölkerung mit lebenswichtigen Gütern sowie die Aufrechterhaltung des Personen- und Güterverkehrs. Arbeitseinweisungen seien aber auch erforderlich, „um arbeitsscheue Elemente in den wirtschaftlichen Wiederaufbau einzugliedern" 31 . Gleichzeitig betonte die DVAS-Abteilung, daß das Prinzip der Freiwilligkeit Vorrang genießen müsse. Während sich die Abteilung III a zum Entwurf ablehnend äußerte ${ }^{32}$, gab die Juristische Abteilung teilweise ihre Zustimmung ${ }^{33}$. Offen kritisiert wurde dagegen auch von ihr der Versuch, Arbeitseinweisungen als sozial disziplinierendes Instrument einzusetzen. Die Ausarbeitung einer Verordnung über die Arbeitseinweisung zog sich allerdings in die Länge; darauf wird weiter unten noch eingegangen.

Vor allem die Länder drängten die DVAS, eine klare und verständliche Richtlinie zur Lösung von Arbeitsverträgen herauszugeben ${ }^{34}$. Die bestehende Rechtsunsicherheit hatte sich dadurch ergeben, daß in der Praxis eine Zustimmung des Arbeitsamtes nicht eingeholt wurde, wenn ein beiderseitiges Einverständnis vorlag. Die Arbeitsverwaltung in den Ländern bestand darauf, daß diese prinzipiell eingeholt werden müsse. Auf einer Konferenz der Landesämter für Arbeit und Sozialfürsorge am 13./14. März 1947 konnte noch keine Einigung erzielt werden. Der SMAD-Mitarbeiter Schaposchnikow, der bei der Frage der Arbeitsvertragsauflösung eine Zustimmung des zuständigen Arbeitsamtes für unentbehrlich hielt, räumte gegenüber DVAS-Vertretern ein, daß der Kontrollratsbefehl „Zweifel in der Auslegung" zulasse ${ }^{35}$. Die Juristische Abteilung brachte zum Anweisungsentwurf der Abteilung I b noch einige Änderungsvorschläge ein, die insgesamt eine weitere Stärkung der Eingriffsmöglichkeiten der Arbeitsämter bedeute-

29 Ebenda. S. 4, Punkt 5.

$30 \mathrm{BAB}, \mathrm{DQ} 2 / 63$, Anweisungsentwurf der DVAS-Abt. I b vom 25. 3. 1947, S. 1.

31 Ebenda, S. 2.

32 BAB, DQ 2/63, Abt. III a am 28. 3. 1947 an Abt. I b.

33 Ebenda, Juristische Abt. am 9. 4. 1947 an Abt. I b.

34 BAB, DQ 2/1767, Ministerium für Wirtschaft, Arbeit und Verkehr des Landes Thüringen am 7. 5. 1947 an die DVAS.

35 Ebenda, Abt. I b am 12. 4. 1947 an Brack. 
ten und vor allem ein Beschwerdeverfahren einführten ${ }^{36}$. Alle Vorschläge, denen die Abteilung III a zustimmte ${ }^{37}$, fanden sich im übrigen in der endgültigen Fassung wieder, die am 16. Mai als Dienstanweisung zum Kontrollratsbefehl Nr. 3 (Lösung von Arbeitsverhältnissen) ${ }^{38}$ veröffentlicht wurde. Gleichzeitig hob die DVAS die Anweisung vom 12. Juni 1946 wieder auf. Nun konnten die Landesverwaltungen entsprechende Rundverfügungen an die Arbeitsämter herausgeben. Aus diesen geht unzweideutig hervor, daß die Diensteinweisung die Arbeitnehmer stärker an die Betriebe binden und insgesamt die Fluktuation in der SBZ eindämmen sollte ${ }^{39}$. Gleichzeitig stellte dies auch ein Instrument zur Verhinderung von Massenentlassungen dar. Voraussetzung war allerdings, daß die Arbeitsämter ihren Zuständigkeitsbereich vollständig erfassen und kontrollieren konnten.

Die Eingriffe, welche die Dienstanweisung den Arbeitsämtern einräumte, wurden von der DVAS durchaus erkannt und in Beziehung gesetzt zu den enormen Aufbauarbeiten in der SBZ, die eine solche arbeitsrechtliche Regelung zwingend erforderlich machten: Das „Chaos, die Erbschaft des Hitlerregimes, in der sich die deutsche Volkswirtschaft zur Zeit befindet“, könne nur durch eine „planmäßige Aufbauarbeit" beseitigt werden ${ }^{40}$. Dazu sei eine Einschränkung des Einstellungsund Kündigungsrechtes für Unternehmer und Arbeitnehmer notwendig. Dieses bedeute „naturgemäß auch eine Einschränkung der Freizügigkeit für die Beteiligten“, müsse aber im Gesamtinteresse der Bevölkerung hingenommen werden. Es sei selbstverständlich, daß die Arbeitsämter nur in Ausnahmefällen Arbeitseinweisungen vornehmen dürften. Andererseits betonte die DVAS-Abteilung, daß dieses Instrument ein wirksames Mittel sei, um gegen „arbeitsscheue Elemente“ vorgehen zu können: „Jeder Arbeitsfähige ist heute verpflichtet zu arbeiten, denn nur so kann die allgemeine Not allmählich beseitigt werden." ${ }^{41}$ Hintergrund für diese Forderung war die Tatsache, daß die Arbeitsverwaltung widerständiges Verhalten unter der Bevölkerung registrierte. Der brandenburgische Minister für Arbeit und Sozialwesen Schwob erklärte anläßlich einer Amtsleitertagung, daß vor allem „viele junge Leute unser Gebiet [verlassen], um sich vor einer Arbeitseinweisung zu drücken“" ${ }^{42}$. Bereits zu diesem Zeitpunkt kristallisierte sich der enge Zusammenhang von Arbeitsverpflichtung und Westflucht heraus. Es kann festgehalten werden: Auch wenn die Pflicht zur Arbeit erst im Arbeitsgesetzbuch von 1961 festgeschrieben worden ist, so lassen sich doch bereits in dieser frühen Phase erste Ansätze dazu erkennen.

Die Dienstanweisung zum Kontrollratsbefehl Nr. 3 schuf kein neues Recht, sondern stellte vielmehr eine „amtliche und authentische Interpretation der Zweifelsfragen dar", wie die Juristische Abteilung der DVAS in einem internen Ver-

36 BAB, DQ 2/262, Bl. 24 f., Juristische Abt. am 2. 5. 1947 an Abt. I b.

3 BAB, DQ 2/1767, Abt. III a am 6. 5. 1947 an Vizepräsident Herm.

38 Arbeit und Sozialfürsorge 2 (1947), S. $233 \mathrm{f}$.

$34 \mathrm{BAB}, \mathrm{DQ} 2 / 1767$, Rundverfügung VIII 1000/R 41 des thüringischen Ministerums für Wirtschaft, Arbeit und Verkehr vom 9. 7. 1947 an alle Ämter für Arbeit und Sozialfürsorge und deren Nebenstellen.

to Ebenda, Vermerk der Abt. I vom 26. 6. 1947, S. 1.

+1 Ebenda, S. 2.

t2 $\mathrm{BAB}, \mathrm{DQ} 2 / 2030$, Protokoll über die Amtsleitertagung im Landesarbeitsamt Potsdam am 15. 7. 1947. 
merk treffend notierte ${ }^{43}$. Der Berliner Zentralverwaltung ging es dabei vor allem um eine Vereinheitlichung einzelner arbeitsrechtlicher Bestimmungen für die gesamte SBZ, die allerdings auch gegen die Landesverwaltungen durchgesetzt werden mußte. Darüber hinaus verfolgte die DVAS das Ziel, die Arbeitsgerichte als Kontrollinstanz langfristig auszuschalten. Dazu wurde in der Dienstanweisung ein eigenes Beschwerdeverfahren eingeführt. Angesichts dieser Rechtslage verbiete es sich - so die Juristische Abteilung - , daß ein Arbeitsgericht „die Verwaltungsakte der Arbeitslenkungsbehörden nachprüft" ${ }^{\text {"44 }}$.

Im Laufe des Sommers 1947 entwickelte sich eine Debatte um eine weitere Bestimmung des Kontrollratsbefehls Nr. 3, welche die Vergabe von Lebensmittelkarten an die Registrierung bei den Arbeitsämtern band. Gegen einen automatischen Entzug der Lebensmittelkarten sprach sich wiederum die Juristische Abteilung aus, mit einem bemerkenswerten Vergleich: Selbst „ein Raubmörder [erhalte] am Tage der Hinrichtung noch immer seine Ration"45. Mit keinem Wort sei im Befehl die Rede davon, daß die Arbeitsverwaltung diese drakonische Strafe verhängen dürfe, die gleichbedeutend sei mit einem „Todesurteil des Verhungernlassens." Dagegen wandte sich die Abteilung I b und berief sich dabei auf das Prinzip der Gleichbehandlung: Wenn man "dem einen das Recht zubillige, trotz seiner Arbeitsverweigerung den Anspruch auf Lebensmittel stellen zu dürfen", dann müsse man allen dieses Recht zubilligen ${ }^{46}$. Das sei im übrigen eine „absolut soziale, ja sozialistische" Auffassung. Eine Einigung konnte noch nicht gefunden werden, so daß es letztlich den Landesämtern bzw. Arbeitsämtern überlassen blieb, inwieweit sie sich an diese gesetzliche Regelung hielten. In der unmittelbaren Nachkriegszeit mit seiner mangelhaften Ernährungslage blieb die Androhung des Entzugs von Lebensmittelkarten ein hartes Sanktionsmittel.

Einzelne Arbeitsgerichte erkannten die Dienstanweisung zunächst nicht an, sondern orientierten sich weiterhin an der alten arbeitsrechtlichen Ordnung. So vertraten beispielsweise einzelne Arbeitsrichter in Sachsen-Anhalt den Standpunkt, daß diese erst durch ein entsprechendes Landesgesetz verbindlich sein könne ${ }^{47}$. Das machte deutlich, wie schwierig es war, Entscheidungen auf zentraler staatlicher Ebene in den Ländern umzusetzen. Letztlich förderte dies auf seiten der SED-Führung und der DVAS-Leitung das Bestreben, Einfluß auf die personelle Zusammensetzung der Arbeitsgerichte zu nehmen und deren Kompetenzen langfristig zurückzudrängen.

Die Dienstanweisung zum Kontrollratsbefehl regelte erstmals den Beschwerdeweg bei Entscheidungen der Arbeitsämter. Ansprechpartner für die Betroffenen waren die Beratungsausschüsse bei den Arbeitsämtern, die mit dieser Anweisung eine nicht unwichtige Aufgabe erhielten. Auch gegen die Entscheidung des Beratungsausschusses konnte eine Beschwerde vorgetragen werden; in diesem Fall entschied dann letztlich das Landesamt für Arbeit und Sozialfürsorge. Beide Beschwerdewege hatten jedoch keine aufschiebende Wirkung. Die DVAS-Abteilung

43 BAB, DQ 2/262, Bl. 27 f., Juristische Abt. am 1. 7. 1947 an Abt. I b.

4 Ebenda, Bl. 39, Juristische Abt. am 11.7. 1947 an Abt. III a.

4 Ebenda.

+6 BAB, DQ 2/262, Bl. 41 f., hier Bl. 42, Abt. I b am 26. 7. 1947 an Abt. III a.

47 Ebenda, Bl. 46, Regierungsrat Dr. Wagner am 20. 8. 1947 an Helm (DVAS). 
I b sprach sich gegen diesen Funktionszuwachs der Beratungsausschüsse aus und erhielt dafür auch Unterstützung auf einer Arbeitstagung der DVAS am 19./20. August 1947 in Rostock ${ }^{48}$. Auf dieser Tagung wurde übereinstimmend festgestellt, daß die Beratungsausschüsse nach der Kontrollratsdirektive Nr. 29 nur beratend tätig sein sollten. Deshalb gehe die Dienstanweisung weit über die ursprünglich zugeteilten Befugnisse hinaus. Kurz darauf machte die Juristische Abteilung deutlich, daß die Dienstanweisung , in ihrem materiellen Inhalt in vollem Umfange" auf dem Befehl des Alliierten Kontrollrates beruhe und nur eine „Klarstellung gewisser Zweifelsfragen" herbeigeführt habe ${ }^{49}$. Sie begründete die Einführung des Beschwerdeverfahrens bei den Beratungsausschüssen mit dem Hinweis auf die "demokratische[n] Selbstverwaltungsprinzipien“. Die Juristische Abteilung hatte gegen die von der Abteilung I $b$ vorgebrachten Bedenken nichts einzuwenden und schlug wenige Tage später eine Regelung vor, die eine Mitwirkung der Beratungsausschüsse nicht mehr vorsah ${ }^{50}$. Gleichzeitig schlug sie vor, wie bei Arbeitseinweisungen so auch bei Kündigungen das Einspruchsverfahren den Beschwerdeausschüssen zu übertragen. Bedenken wurden aber auch von seiten der Länder vorgebracht. So erklärte das thüringische Ministerium für Arbeit und Sozialwesen, daß eine Dienstanweisung, „die schon ihrem Wort nach rein internen Charakter trägt, kein neues Rechtsmittelverfahren schaffen" könne ${ }^{51}$. Die Errichtung von Beschwerdeinstanzen sei nur in Form eines Gesetzes oder einer Verordnung möglich. Die Juristische Abteilung der DVAS stimmte den vorgetragenen Bedenken grundsätzlich zu, wandte sich aber gleichzeitig gegen eine arbeitsrechtliche Änderung oder Ergänzung. Das Argument klang dabei nicht sehr überzeugend: Da die Dienstanweisung bereits ein halbes Jahr in Kraft sei, könne sich die DVAS nur auf den Standpunkt stellen, „daß es sich bei ihr um etwas Ähnliches handelt, wie die früher im Reichsmaßstab und jetzt noch in den Ländern üblichen Ministerialerlasse" 52 . Nach Ansicht der Juristischen Abteilung konnten diese Erlasse - verwaltungsrechtlich gesehen - durchaus sogenannte Rechtssätze enthalten. Was die Frage nach den Entscheidungsbefugnissen für die Beratungsausschüsse anbelangte, so verwies die Juristische Abteilung etwas hilflos auf die Befehlslage von seiten der sowjetischen Besatzungsmacht. Nur so glaubte man das Handeln der DVAS noch legitimieren zu können: „Wir können [...] jedoch nunmehr, um das Ansehen der DVAS nicht zu gefährden, gar nicht anders argumentieren, als daß wir den Standpunkt einnehmen, die Dienstanweisung ist auf Anordnung der SMAD erfolgt und diese kann die Zuständigkeit der Beratungsausschüsse auch in der dargestellten Form erweitern." ${ }^{53}$ Eine Einigung konnte auch auf der Arbeitstagung der DVAS am 6./7. Januar 1948 in Leipzig nicht erzielt werden. Auffallend war die Tatsache, daß die DVAS die Ländervertreter nicht zu überzeugen vermochte. Die Präsidentin des sächsischen Landesarbeitsamtes, Hildegard Heinze, hielt sogar die Ausarbeitung einer neuen Verordnung über die Lö-

48 Ebenda, Bl. 52, Abt. I b am 26. 8. 1947 an Juristische Abt.

49 Ebenda, Bl. 53, Juristische Abt. am 28. 8. 1947 an Abt. I b.

5o Ebenda, Bl. 54, Juristische Abt. am 5. 9. 1947 an Abt. I b.

51 Ebenda, Bl. 69, Ministerium für Arbeit und Sozialwesen des Landes Thüringen am 29. 12. 1947 an die DVAS.

52 Ebenda, Bl. 70, Juristische Abt. am 31. 12. 1947 an Abt. I b, S. 1.

53 Ebenda. 
sung von Arbeitsverhältnissen für unerläßlich ${ }^{54}$. Erst nachdem die „Verordnung über die Sicherung und den Schutz der Rechte bei Einweisungen von Arbeitskräften" veröffentlicht worden war, machte sich die HVAS an die Ausarbeitung einer Durchführungsbestimmung zur Errichtung von Beschwerdeausschüssen, die dann am 22. Oktober 1948 in Kraft trat ${ }^{55}$. Eine enge Verbindung zu den Beratungsausschüssen blieb aber bestehen, da diese die Beisitzer der Beschwerdeausschüsse auswählen und berufen konnten. Darüber hinaus mußten die Beisitzer Mitglieder des Beratungsausschusses sein.

Die SMAD verfolgte die Kontroverse über die Auslegung des Kontrollratsbefehls Nr. 3 zwischen einzelnen Abteilungen der DVAS mit großem Unverständnis. Auf einer gemeinsamen Besprechung mit Vertretern der Berliner Zentralverwaltung stellte der SMAD-Mitarbeiter Iljuschin fest, daß der Befehl klar und eindeutig formuliert sei und er die Meinungsverschiedenheiten nicht verstehen könne ${ }^{56}$. Bei der Interpretation der Bestimmungen zum Arbeitsplatzwechsel betonte Iljuschin, daß für diesen Fall die Zustimmung des Arbeitsamtes stets einzuholen sei, und übte damit Kritik an der Juristischen Abteilung.

Meinungsverschiedenheiten ergaben sich auch bei den Strafbestimmungen des Kontrollratsbefehls Nr. 3, da einzelne Landesverwaltungen noch gesonderte Verordnungen verabschieden wollten. So hatte etwa das sächsische Ministerium für Arbeit und Sozialfürsorge einen entsprechenden Entwurf ausgearbeitet, der allerdings vom dortigen Justizministerium einer kritischen Bewertung unterzogen wurde. Hauptkritikpunkt war, daß mit dieser Verordnung eine „doppelte Bestrafung“ erfolgen könnte, da bereits der Kontrollratsbefehl entsprechende Strafen vorsehe ${ }^{57}$. Eine strafrechtliche Verfolgung solle aber - so das sächsische Ministerium der Justiz weiter - nicht bei Ordnungswidrigkeiten, sondern nur bei „kriminelle[m] Unrecht" einsetzen. Dagegen schloß der Verordnungsentwurf bei der Verhängung einer Ordnungsstrafe die strafrechtliche Verfolgung nicht aus ${ }^{58}$. In dem Zusammenhang tauchte auch wieder die Frage nach Entzug der Lebensmittelkarten als Sanktionsmittel auf. Anlaß dafür war unter anderem die offensichtlich unterschiedliche Handhabung in den Ländern. Deshalb stellte die Juristische Abteilung unmißverständlich fest, daß die Verhängung dieses Strafmittels im Sinne des Kontrollratsbefehls nur die Herabstufung auf die niedrigste Stufe bedeuten könne. Die Lebensmittelkarten durften demzufolge nicht vollständig entzogen werden, da dieser Schritt ansonsten mit „einem Todesurteil auf Verhungernlassen gleichzusetzen ist" ${ }^{\text {59}}$. Daraus wurde deutlich, daß auch in dieser Frage keine Einigkeit zwischen den Abteilungen der DVAS herrschte. Die Juristische Abteilung kündigte an, daß sie eine endgültige Entscheidung durch das Präsidium der DVAS veranlassen würde. Nach den Vorstellungen dieser Abteilung sollte der

54 BAB, DQ 2/1537, Niederschrift über den Verlauf der Arbeitstagung der DVAS in Leipzig am 6./7. 1. 1948, S. 32.

55 Arbeit und Sozialfürsorge 3 (1948), S. $449 \mathrm{f}$.

56 BAB, DQ 2/2040, Bl. $83 \mathrm{f}$., Niederschrift der Abt. I b über eine Besprechung mit der SMAD in Karlshorst am 30. 8. 1947.

57 BAB, DQ 2/262, Bl. 65, Ministerium der Justiz der Landesregierung Sachsen am 18. 10. 1947 an die DJV. Der Verordnungsentwurf befindet sich in: ebenda, Bl. 66.

58 Ebenda, Bl. 66.

59 BAB, DQ 2/262, Bl. 57f., hier Bl. 57, Jurist. Abt. am 7. 11. 1947 an Abt. III a. 
Entzug der Lebensmittelkarten jedoch nicht von einem Gericht ausgesprochen werden, sondern vielmehr eine Verwaltungsangelegenheit bleiben. Somit ermächtigte der Befehl die Verwaltungen dazu, diese Strafe auszusprechen, er verpflichtete sie allerdings nicht zu diesem Schritt ${ }^{60}$. Dieser Meinung schloß sich daraufhin die Abteilung III a der DVAS an ${ }^{61}$. Gleichzeitig machte die Juristische Abteilung darauf aufmerksam, daß die SMAD eine strenge Anwendung des Kontrollratsbefehls wünsche ${ }^{62}$. Am 11. Februar 1948 legte die DVAS-Abteilung I b einen Entwurf für ein Rundschreiben an die Landesarbeitsämter vor, das zur „Bekämpfung von Arbeitsvertragsbrüchen oder unentschuldigtem Fernbleiben von der Arbeit“ die Sperrung der Lebensmittelkarte vorsah ${ }^{63}$. Letztlich schreckten die deutschen Zentralverwaltungen aber vor einer zu rigide erscheinenden Praxis zurück und beließen es - arbeitsrechtlich gesehen - zunächst bei einer Koppelung der Registrierung der Bevölkerung mit der Kontrolle bei der Lebensmittelkartenausgabe. Dazu erließen die Deutsche Verwaltung für Handel und Versorgung, die DVAS und die Deutsche Zentralfinanzverwaltung am 13. Februar 1948 einen gemeinsamen Runderlaß64.

Das Ministerium für Sozialwesen von Mecklenburg-Vorpommern warf die grundsätzliche Frage nach der rechtlichen Bedeutung einer Arbeitseinweisung auf: „Entweder betrachtet man die Arbeitseinweisung nur als zwangsweise Anordnung oder Herstellung eines privatrechtlichen Arbeitsverhältnisses und behandelt die Eingewiesenen dann gleichstehend wie alle privatrechtlich im Arbeitsverhältnis stehenden Personen. "65 Im letztgenannten Fall war aus Sicht des mecklenburgischen Ministeriums nur eine zivilrechtliche Verfolgung möglich. Von dieser Frage schien insgesamt die Wahl der Sanktionsmittel abhängig zu sein. Die Juristische Abteilung der DVAS wich dieser Anfrage jedoch aus und beschränkte sich auf eine erneute Interpretation des Kontrollratsbefehls $s^{66}$. Danach galt die Strafandrohung nur für Arbeitslose, die sich einer Arbeitseinweisung widersetzten, und nicht für Personen, die bereits in einem Beschäftigungsverhältnis standen. Für diese Gruppe der „Arbeitsbummelanten“ galten die Strafbestimmungen der kurz zuvor im engen Zusammenhang mit dem SMAD-Befehl Nr. 234 veröffentlichten Arbeitsordnung ${ }^{67}$. Die DVAS mußte bald erkennen, daß ein Widerspruch bestand zwischen der Dienstanweisung, die den Arbeitsämtern ein Widerspruchsrecht gegen Entlassungen einräumte, und der Arbeitsordnung, nach der Verstöße gegen die arbeitsrechtlichen Bestimmungen unter anderem mit einer Entlassung bestraft werden konnten. Das hatte offenbar dazu geführt, daß einzelne Betriebe sogenannte Bummelanten entließen, ohne erst die in der Arbeits-

60 Ebenda, Bl. 62, Juristische Abt. am 4. 12. 1947 an die Abt. III a.

6i Ebenda, Bl. 67, Abt. III a am 12.12.1947 an DJV.

62 Ebenda, Bl. 62.

$63 \mathrm{BAB}, \mathrm{DQ} 2 / 111, \mathrm{Bl} .80-82$.

64 Arbeit und Sozialfürsorge 3 (1948), S. 223 f., Gemeinsamer Runderlaß Nr. 1/48 betr. Überprüfung der Arbeitsverhältnisse der im arbeitsfähigen Alter stehenden Lebensmittelkartenempfänger.

65 BAB, DQ 2/262, Bl. 59, Ministerium für Sozialwesen von Mecklenburg-Vorpommern am 13. 11. 1947 an die DVAS (Juristische Abt.).

66 Ebenda, Bl.61, DVAS am 28.11. 1947 an Ministerium für Sozialwesen der Landesregierung Mecklenburg.

67 Arbeit und Sozialfürsorge 2 (1947), S. 454-456, Arbeitsordnung für volkseigene, SAG- und andere Betriebe in der SBZ vom 13. 10. 1947. 
ordnung vorgesehenen übrigen Strafmaßnahmen heranzuziehen ${ }^{68}$. Dadurch hatte sich die Fluktuation der Arbeitskräfte erhöht, welche die Dienstanweisung ursprünglich stärker reglementieren sollte.

Anfang 1948 wuchs der Druck auf die DVAS, gezielter gegen „Arbeitsbummelanten" und Arbeitsvertragsbrüche vorzugehen und die strafrechtlichen Regelungen im Arbeitsrecht zu konkretisieren. Zu diesem Zeitpunkt wurde innerhalb der DVAS diskutiert, eine gesonderte Verordnung zu erlassen, welche die Strafen bei Nichtbefolgung des Kontrollratsbefehls Nr. 3 beinhalten sollte. Die Veröffentlichung einer eigens dazu aufgesetzten Verordnung befürwortete im übrigen auch auf Anfrage die Deutsche Zentralverwaltung für Justiz ${ }^{69}$. Der Entwurf eines Rundschreibens, den die Abteilung I b am 11. Februar aufsetzte, sah teilweise drastische Mittel vor. So sollten Arbeitskräfte, die der Arbeit unentschuldigt fernblieben, polizeilich vernommen werden ${ }^{70}$. Es war wiederum die Juristische Abteilung, die deutliche Kritik an diesem Vorstoß übte. Sie beanstandete vor allem die enge Verknüpfung zwischen „polizeilichen und arbeitsamtlichen Maßnahmen" "71. Es sei sozialpolitisch nicht besonders "glücklich“, den SMAD-Befehl Nr. 234 und die Arbeitsordnung "mit immerhin recht massiven Repressalien in unmittelbaren Zusammenhang zu bringen"72. Statt dessen sollten die Maßnahmen gegen „Arbeitsbummelanten" - so die Juristische Abteilung - in erster Linie auf den Befehl Nr. 3 des Alliierten Kontrollrates gestützt werden. Einig war man sich in der DVAS darüber, daß die Arbeitsunfähigkeit von einer Ärztekommission festzustellen war. So stand es auch im Kontrollratsbefehl (Ziffer 11)73. Die Arbeitsverwaltung verstärkte ihr Vorgehen gegen die „Arbeitsbummelanten“; dabei hing die Intensität der Maßnahmen von der Motivation der Mitarbeiter des jeweiligen Arbeitsamtes ab. So veröffentlichte etwa das Amt für Arbeit und Sozialfürsorge von Haldensleben im Amtlichen Mitteilungsblatt des Kreises eine Liste von Personen, die in Schnellgerichtsverfahren zu Gefängnisstrafen zwischen sechs und elf Wochen verurteilt worden waren; 18 namentlich genannte Personen hatten sich der Aburteilung durch Flucht entzogen ${ }^{74}$. Das Arbeitsamt hatte daraufhin die örtlichen Polizeidienststellen beauftragt, die Gesuchten zu inhaftieren. Das rigorose Vorgehen schlug sich auch in der sprachlichen Ausdrucksweise nieder und machte gewisse Parallelen zum NS-Regime und dessen wirtschafts- und sozialpolitischen Vorstellungen 75 deutlich: „Dieses verschärfte Vorgehen gegen Arbeitsbummelanten und Arbeitsverweigerer, die auf Kosten der werktätigen Bevölkerung ein be-

$68 \mathrm{BAB}, \mathrm{DQ} 2 / 1891, \mathrm{Bl} .12$, Auszug aus den Berichten, Mappe 5, über Betriebskontrollen bzw. über Berichte der Arbeitsministerien, 10.1.1948.

$69 \mathrm{BAB}, \mathrm{DQ} 2 / 262, \mathrm{Bl} .72$, Vizepräsident Herm am 18. 2. 1948 an Ministerium für Sozialwesen des Landes Mecklenburg.

$70 \mathrm{BAB}, \mathrm{DQ} 2 / 111, \mathrm{Bl} .82$.

71 BAB, DQ 2/262, Bl. 83, Juristische Abt. am 24. 2. 1948 an Abt. I b.

72 Ebenda.

$73 \mathrm{BAB}, \mathrm{DQ}$ 2/262, Bl. 73, Abt. I b am 24. 2. 1948 an Juristische Abt. Die Juristische Abt. verwies dagegen auf die Ziffer 18, die bei der Begründung der amtsärztlichen Untersuchung herangezogen werden müßte. Vgl. ebenda, Bl. 74, Juristische Abteilung am 27. 2. 1948 an Abt. I b.

$74 \mathrm{BAB}, \mathrm{DQ} 2 / 137, \mathrm{Bl}$. 274, Auszug aus dem Amtlichen Mitteilungsblatt für den Kreis Haldensleben vom 14. 2. 1948 .

75 Vgl. dazu: Geyer, Soziale Sicherheit und wirtschaftlicher Fortschritt; Herbst, Der Totale Krieg; Recker, Nationalsozialistische Sozialpolitik. 
quemes Leben führen wollen, gibt den ehrlichen Arbeitern die Gewißheit, daß ihre Arbeit anerkannt wird und alles getan wird, sie gegen die Parasiten der heutigen Notzeit zu schützen."76 Die DVAS verwies in einem Rundschreiben auf die bestehende Arbeitsordnung vom 13. Oktober 1947 und mahnte die Einhaltung der darin festgelegten Vorgehensweise an ${ }^{77}$. Das bedeutete aber keineswegs, daß die DVAS einen konzilianteren Kurs verfolgte. Wenig später übernahm die Berliner Zentralverwaltung die Position des FDGB-Bundesvorstandes und beanstandete, daß das Arbeitsamt Haldensleben ,nicht energisch genug gegen notorische Arbeitsbummelanten vorgehe"78. Die Kritik bezog sich offensichtlich auf die Personengruppe, die sich einer Verurteilung bislang entziehen konnte. Die örtlichen Polizeidienststellen wurden noch im Frühjahr 1948 zur Unterstützung der Arbeitsämter "bei der Hebung der Arbeitsmoral“ herangezogen ${ }^{79}$.

Zusammenfassend sei nochmals darauf hingewiesen, daß sowohl der SMADBefehl Nr. 65 als auch der Kontrollratsbefehl Nr. 3 einen ersten arbeitsrechtlichen Rahmen für die Registrierung der arbeitsfähigen Bevölkerung aber auch für Arbeitseinweisungen bzw. -verpflichtungen absteckten. In der Praxis, d.h. vor allem in der täglichen Arbeit der Arbeitsverwaltung, zeigten sich jedoch rasch die Unzulänglichkeiten und Widersprüchlichkeiten, die beide Befehle enthielten. Das bedeutete letztlich, daß die DVAS als oberste und leitende Instanz der deutschen Arbeitsbehörde in der SBZ daran gehen mußte, in Form von Verordnungen diese Lücken zu füllen und arbeitsrechtliche Bestimmungen zu präzisieren.

\section{Verordnung über die Sicherung und den Schutz der Rechte bei Einweisungen von Arbeitskräften}

Ausgangspunkt für diese Verordnung waren die Bestimmung des Kontrollratsbefehls Nr. 3, welche die Zwangseinweisung in Arbeit zu regeln hatte, und der SMAD-Befehl Nr. 153 vom 29. November 194580. Dieser sowjetische Befehl räumte den Arbeitsämtern das Recht ein, Arbeitslose „ohne Rücksicht auf den Beruf“ zu vermitteln. Außerdem wurden der DVAS-Präsident sowie die Ministerpräsidenten ermächtigt, eine Umverteilung von Arbeitskräften unter den Ländern bzw. innerhalb eines Landes vorzunehmen. Damit schien die arbeitsrechtliche Lage eindeutig zu sein. Dennoch war in der Arbeitsverwaltung zunächst unklar, ob davon alle Erwerbstätigen oder nur die Arbeitslosen betroffen sein sollten. So hatte etwa die Staatsanwaltschaft beim Landgericht Dresden entsprechende Strafverfahren mit der Begründung eingestellt, die gesetzlichen Regelungen seien nur auf Arbeitslose anzuwenden ${ }^{81}$. Dagegen hob die Präsidentin des sächsischen Landesarbeitsamtes hervor, daß die Vollmachten der Arbeitsämter "gegenstandslos wären, wenn sie sich nur auf Arbeitslose erstrecken sollten" 82 .

76 BAB, DQ 2/137, Bl. 274.

77 Ebenda, B1. 276, Rundschreiben Nr. 206 der DVAS vom 16. 3. 1948.

78 Ebenda, Bl. 271, DVAS (Abt. I b) am 25. 3. 1948 an FDGB-Bundesvorstand (HA 3).

79 Ebenda, Bl. 277, DVdI am 21. 4. 1948 an die Leiter der Landespolizeibehörden.

80 Arbeit und Sozialfürsorge 1 (1946), S. $3 \mathrm{f}$.

81 BAB, DQ 2/2080, Bl. 6, Landesarbeitsamt Sachsen am 26. 11. 1946 an den Generalstaatsanwalt der Landesverwaltung Sachsen.

82 Ebenda. 
Die Juristische Abteilung der DVAS vertrat dazu die Meinung, daß „auch bereits Erwerbstätige auf einen anderen Arbeitsplatz umgesetzt werden können"83. Sowohl der DVAS als auch dem Landesarbeitsamt ging es darum, die Zuständigkeiten der Arbeitsämter im Sinne einer umfassenden Arbeitskräftelenkung auszubauen.

Bei der Ausarbeitung einer Verordnung nahm Thüringen wiederum eine Vorreiterfunktion ein und legte Anfang 1947 einen ersten Entwurf vor, der zunächst nur innerhalb der Landesverwaltung diskutiert wurde ${ }^{84}$. Dieser legte fest, daß nicht nur Erwerbslose, sondern auch Personen in einem Arbeitsverhältnis in eine neue Arbeit eingewiesen werden konnten. Von dieser Regelung waren auch die Selbständigen betroffen. Die Hauptabteilung Arbeit und Sozialfürsorge im thüringischen Ministerium für Wirtschaft, Arbeit und Verkehr begründete dieses Vorgehen mit dem Hinweis, daß „einzelne Wirtschaftszweige besonders bei Handel und Gewerbe als überbesetzt angesehen werden müssen“. Die Anforderungen der sowjetischen Besatzungsmacht könnten vor allem bei kurzfristigen Aufträgen „nicht immer durch alleinige Heranziehung der unselbständig Beschäftigten abgedeckt werden" 85 . Der Entwurf sah offensichtlich eine zeitliche Befristung der Arbeitseinweisung nicht vor. Bestimmte Bevölkerungsgruppen waren laut SMADBefehl Nr. 153 von der Melde- und Einsatzpflicht befreit: Frauen mit Säuglingen bzw. Kindern unter sechs Jahren, Schüler, „Kulturschaffende“, Freiberufler und Invaliden, die zwei Drittel und mehr von ihrer Arbeitskraft verloren hatten. Die SMAD plante vermutlich eine Erweiterung dieses Personenkreises. Das thüringische Justizministerium hatte nur wenige Änderungsvorschläge ${ }^{86}$. Die DVAS-Abteilung I b benötigte etwas mehr Zeit und konnte erst am 21. März 1947 ihren Entwurf vorlegen, der die Überschrift „Gesetz über die Regelung von Arbeitseinweisungen" trug ${ }^{87}$. Danach sollten die Arbeitseinweisungen auf die „Durchführung von Arbeiten vordringlicher Art" beschränkt bleiben. Im einzelnen zählte die Abteilung I b dazu sowjetische Auftragsarbeiten, Arbeiten aufgrund von Verpflichtungen zu anderen Staaten, Tätigkeiten zur Behebung eines "öffentlichen Notstandes“ sowie die Versorgung der von der DVAS „als lebenswichtig anerkannten" Wirtschaftsbranchen und Betriebe mit Arbeitskräften. Ausnahmen sollten nur bei Parlamentsabgeordneten und Betriebsratsmitgliedern gemacht werden. Als Regelzeit setzte der Entwurf sechs Monate fest, ließ aber auch die Möglichkeit einer Verlängerung bis zu einem Jahr offen. Darüber hinaus wurden ausführlich die Einspruchsmöglichkeiten gegen einen Einweisungsbeschluß erläutert. Beide Entwürfe ergänzten sich teilweise. Während der Schwerpunkt des thüringischen Gesetzentwurfes auf der Ausnahmeregelung sowie den Strafbestimmungen lag, nahm der Beschwerdeweg im DVAS-Entwurf größeren Raum ein.

83 BAB, DQ 2/262, Bl. 1 f., Juristische Abt. am 27. 11. 1946 an Abt. II. Diese Rechtsauffassung teilten die Landesarbeitsämter kurz darauf den Arbeitsämtern mit. Vgl. ebenda, Bl. 3 f., Landesarbeitsamt Potsdam am 30.11. 1946 an die 27 Arbeitsämter der Provinz Brandenburg.

s4 Vgl. ThHStA, Land Thüringen, Ministerium für Wirtschaft und Arbeit, Bd. 3694, Bl. 1.

85 Ebenda.

86 ThHStA, Land Thüringen, Ministerium für Wirtschaft und Arbeit, Bd. 3694, Bl. 7, Ministerium für Justiz am 27. 1. 1947 an Ministerium für Wirtschaft, Arbeit und Verkehr. In der Anlage befindet sich ein überarbeiteter Entwurf. Vgl. ebenda, Bl. 12-14.

$87 \mathrm{BAB}, \mathrm{DQ} 2 / 63$. 
Nach Ansicht der Hauptabteilung Arbeit und Sozialfürsorge im thüringischen Ministerium für Wirtschaft, Arbeit und Verkehr war die Herausgabe eines „Gesetzes zur Regelung von Arbeitseinweisungen [...] unbedingt erforderlich" ${ }^{88}$. Als Hauptargument wurde angeführt, daß dieses Zwangsmittel bereits in Branchen eingesetzt worden wäre, die der SMAD-Befehl Nr. 153 ursprünglich gar nicht vorgesehen hätte. Daher müsse die Liste der Wirtschaftszweige erweitert werden. Die bisherige praktische Erfahrung diente auch als Begründung für die zeitliche Verlängerung der Arbeitseinweisung. Die Arbeitsämter müßten die Möglichkeit erhalten, Einweisungen „auch auf unbestimmte Zeit auszusprechen“89. Die DVAS erkannte die Notwendigkeit, die mit der Arbeitseinweisung angefallenen Fragen einheitlich durch eine Verordnung zu klären. Auf einer Arbeitstagung am 13./ 14. März 1947 war darüber bereits Einigkeit zwischen den Vertretern der Berliner Zentralverwaltung und denen der Landesämter erzielt worden ${ }^{90}$. Um die Einheitlichkeit der Gesetzgebung in der SBZ zu wahren, bat die DVAS das thüringische Ministerium, den bereits ausgearbeiteten und dem Landtag vorgelegten Verordnungsentwurf wieder zurückzuziehen'1. Dieser Bitte kam das thüringische Ministerium für Wirtschaft, Arbeit und Verkehr kurze Zeit später nach und begrüßte die angekündigte einheitliche Regelung von Arbeitseinweisungen ${ }^{92}$.

Gegen eine Ausweitung und Verschärfung der gesetzlichen Bestimmungen wandte sich die Abteilung III a, die vor allem mit der zeitlichen Ausdehnung der Arbeitseinweisung überhaupt nicht einverstanden war ${ }^{93}$. Daran zeigten sich nicht zum ersten Mal die unterschiedlichen Meinungen zwischen einzelnen Abteilungen der DVAS. Auch die Juristische Abteilung hielt eine „erhebliche Umarbeitung" des Entwurfes der Abteilung I b für unvermeidlich ${ }^{94}$. Dieser enthalte nämlich "einseitige Zwangsmaßnahmen" gegen den Arbeitnehmer ${ }^{95}$. Die Einschränkung der Freizügigkeit des Arbeitnehmers bei der Arbeitsplatzwahl müsse - so die Juristische Abteilung - mit einer Einschränkung der Wahlfreiheit des Arbeitgebers bei der Einstellung von Arbeitskräften korrespondieren. In der Praxis habe sich gezeigt, daß die Arbeitseinweisung in erster Linie die Arbeiter und Angestellten, nicht aber die Unternehmer und Selbständigen treffe. Die Abteilung I $b$ übernahm nur teilweise die vorgebrachten Änderungsvorschläge, eine grundsätzliche Überarbeitung erfolgte nicht. Vor allem die zeitliche Dauer der Arbeitseinweisung wurde auf maximal sechs Monate beschränkt ${ }^{96}$.

Das zuständige Ministerium in Thüringen brachte zum überarbeiteten Entwurf einige Verbesserungsvorschläge ein. So sollten etwa „Spitzenfunktionäre“ der Parteien und Massenorganisationen von der Arbeitseinweisung ausgenommen

88 ThHStA, Land Thüringen, Ministerium für Wirtschaft und Arbeit, Bd. 3694, Bl. 32-34, hier Bl. 33, Abt. I am 24. 3. 1947 an Ministerialdirektor Müller.

89 Ebenda, Bl. 34.

yo ThHStA, Land Thüringen, Ministerium für Wirtschaft und Arbeit, Bd. 3694, Bl. 20, DVAS-Präsident Brack am 29. 3. 1947 an das thüringische Ministerium für Wirtschaftsplanungen [sic], HA Arbeit und Sozialfürsorge.

91 Ebenda.

92 ThHStA, Land Thüringen, Ministerium für Wirtschaft und Arbeit, Bd. 3694, Bl. 29.

93 BAB, DQ 2/63, Abt. III a am 28. 3. 1947 an Abt. I b, S. 2.

9* BAB, DQ 2/261, Bl. 6-10, hier Bl. 7, Juristische Abt. am 1. 4. 1947 an Abt. I b.

95 Ebenda, Bl. 6.

96 BAB, DQ 2/261, Bl. 12-17, hier Bl. 13, 2. Entwurf der Abt. I b vom 12. 4. 1947. 
werden. Gleichzeitig wurde vorgeschlagen, den Gesetzentwurf nicht von den Landesparlamenten verabschieden zu lassen, sondern auf dem Verordnungswege einzuführen. Andernfalls sei damit zu rechnen, daß Änderungen vorgenommen würden, „die den Gedanken der Einheitlichkeit für die gesamte Sowjetzone wieder umstoßen"97. Die Juristische Abteilung der DVAS bedauerte ausdrücklich, daß der Entwurf ohne vorherige Rücksprache bereits den Landesregierungen zugestellt worden war und fügte dem eine leichte Drohung hinzu: „Es darf angenommen werden, daß sich das in diesem Falle vorliegende Mißverständnis nicht noch einmal wiederholt" ${ }^{* 98}$. Inhaltlich wurde kritisiert, daß die vorgetragenen Änderungsvorschläge unberücksichtigt geblieben seien. Gleichzeitig plädierte die Juristische Abteilung dafür, Bestimmungen über Ordnungsstrafen in den Entwurf nicht aufzunehmen. Auf einer Präsidiumssitzung der DVAS am 15. April 1947 konnte immer noch keine Übereinstimmung erzielt werden. Immerhin wurde zwischen den beteiligten Abteilungen vereinbart, bei der Ausarbeitung der Verordnung über Arbeitseinweisungen enger zusammenarbeiten. So sollten etwa Mitarbeiter bei Arbeitsbesprechungen der jeweils anderen Abteilung hinzugezogen werden ${ }^{99}$.

Auch andere Landesverwaltungen hatten gegen den Entwurf der DVAS etwas einzuwenden. So stand der Minister für Arbeit und Sozialpolitik von Sachsen-Anhalt, Leo Herwegen, auf dem Standpunkt, daß das Gesetz von den Landtagen der Länder in Kraft gesetzt werden müsse; der DVAS stehe ein Gesetzgebungsrecht nicht zu ${ }^{100}$. Die Kritik von mehreren Seiten zeigte offensichtlich Wirkung, da die DVAS-Abteilung I b am 9. Mai 1947 die Änderungsvorschläge zum Gesetzentwurf zumindest einmal auflistete ${ }^{101}$. Drei Wochen später lag der neu überarbeitete Entwurf vor, der nur noch als Verordnung ausgewiesen wurde ${ }^{102}$. Die Abteilung I $b$ hatte sich bemüht, Verbesserungsvorschläge vom FDGB aufzugreifen. So wurde etwa der Katalog der „Arbeiten vordringlichster Art“ erweitert. Darüber hinaus unterlagen Parlamentsabgeordnete, Betriebsratsmitglieder, Personen in der Berufsausbildung und "leitende Personen“ des FDGB, der Parteien und der Massenorganisationen, „soweit sie hauptberuflich als solche tätig sind“, nicht der Verordnung. Außerdem begrenzte der Verordnungsentwurf die Arbeitseinweisung auf sechs Monate. Unübersehbar war der Versuch, die mit der Verordnung verbundene Einschränkung der Freizügigkeit so weit wie möglich rechtsstaatlich zu regeln. Dennoch blieb für die Arbeitsverwaltung ein nicht unbeträchtlicher $\mathrm{Ge}-$ staltungsspielraum übrig. Das betraf vor allem die Festlegung der Arbeiten, bei denen Arbeitseinweisungen vorgenommen werden durften. Dagegen schränkte die zeitliche Begrenzung sowie die Möglichkeit, gegen die Einweisung in Arbeit

${ }_{97}$ ThHStA, Land Thüringen, Ministerium für Wirtschaft und Arbeit, Bd. 3694, Bl. 41-43, Ministerium für Wirtschaft, Arbeit und Verkehr (HA Arbeit und Sozialfürsorge) am 23.4. 1947 an die DVAS.

$98 \mathrm{BAB}, \mathrm{DQ} 2 / 261, \mathrm{Bl} .18 \mathrm{f} .$, Juristische Abt. am 24. 4. 1947 an Abt. I b.

$99 \mathrm{BAB}, \mathrm{DQ} 2 / 63$, Mitteilung der Juristischen Abt. vom 28. 4. 1947 an die Abt. I b.

100 BAB, DQ 2/1737, Bl. 61 f., hier Bl. 61, Minister für Arbeit und Sozialpolitik von Sachsen-Anhalt am 8. 5. 1947 an die DVAS.

101 ThHStA, Land Thüringen, Ministerium für Wirtschaft und Arbeit, Bd. 3694, Bl. 44-46.

102 BAB, DQ 2/1737, Bl. 81-85, Entwurf der DVAS (Abt. I b) vom 28. 5. 1947. 
Beschwerde einzulegen (allerdings ohne aufschiebende Wirkung), die Lenkungsmöglichkeiten der Arbeitsämter wieder etwas ein.

Am 2. Juni 1947 legte die Abteilung I b einen geringfügig überarbeiteten Verordnungsentwurf vor ${ }^{103}$, der von der Juristischen Abteilung erneut eingehend kritisiert wurde ${ }^{104}$. Daran zeigte sich das weitgehend zerrüttete Verhältnis zwischen den beiden DVAS-Abteilungen. So stellte die Juristische Abteilung einleitend fest, daß der Entwurf „in seinen Formulierungen und in seinem Aufbau noch nicht den Anforderungen entspricht, die an eine so wichtige, in das Leben der Werktätigen tief eingreifende Verordnung zu stellen sind"105. Erneut wurde die Berücksichtigung der bisherigen Stellungnahmen sowie die konkrete Vereinbarung einer inhaltlichen Aussprache angemahnt. Außerdem beanstandete die Juristische Abteilung, daß der Entwurf an die Deutsche Zentralverwaltung für Justiz gegangen sei, ohne daß zuvor eine „restlose Übereinstimmung“ innerhalb der DVAS erfolgt sei. Neben einer detaillierten, zuweilen auch etwas kleinlichen Einzelkritik hatte sich die Juristische Abteilung entschlossen, einen eigenen Entwurf abzufassen ${ }^{106}$. Dieser unterschied sich in einigen Punkten: So enthielt er etwa eine Bestimmung, wonach die Arbeitseinweisung die Zustimmung des Betriebsinhabers beim Abschluß eines Arbeitsvertrages ersetzen sollte. Darüber hinaus wurde die Personengruppe, die von der Einweisung ausgenommen wurde, um die anerkannten „Opfer des Faschismus“ erweitert. Außerdem hatten beide Entwürfe eine andere Struktur. Ansonsten bestanden aber zwischen beiden Entwürfen keine unüberbrückbaren inhaltlichen Gegensätze. Der Grund für das Zerwürfnis bestand vermutlich darin, daß sich die Juristische Abteilung übergangen fühlte und ihre Kompetenzen bei der Ausarbeitung von Gesetzestexten deutlich machen wollte. Davon zeigte sich die Abteilung I b leicht beeindruckt und legte am 9. Juli 1947 einen neuen Entwurf vor, der eine gewisse Annäherung erkennen ließ, die sich vor allem auf die Bestimmungen zum ruhenden Arbeitsverhältnis bezog ${ }^{107}$. Mit diesem Kompromiß gab sich die Juristische Abteilung jedoch keineswegs zufrieden, sondern forderte eine vollständige Einarbeitung ihrer Verbesserungsvorschläge ${ }^{108}$.

In den ersten Nachkriegsjahren war das Instrument der Arbeitseinweisung kein Spezifikum der SBZ, sondern läßt sich auch in den westlichen Besatzungszonen feststellen. Die ostdeutsche Arbeitsverwaltung registrierte daher auch aufmerksam die Entwicklung auf diesem Gebiet im Westen Deutschlands. Im Gegensatz zur SBZ hatte der Einspruch gegen eine Arbeitsverpflichtung etwa in NordrheinWestfalen aufschiebende Wirkung ${ }^{109}$. Dadurch hatte die Arbeitseinweisung automatisch an Durchschlagskraft verloren, was sich wohl auch in den Statistiken nie-

103 Ebenda, Bl. 97-104, II. Entwurf der Abt. I b vom 2.6. 1947. Im Vergleich zur Fassung vom 28.5. waren einzelne Passagen nur umgestellt und stellenweise neu formuliert worden. Inhaltlich bestanden jedoch keine Unterschiede.

${ }^{104} \mathrm{BAB}, \mathrm{DQ}$ 2/63, Kommentar der Juristischen Abt. vom 16.6. 1947 zum Entwurf der Abt. I b vom 2. 6. 1947 .

105 Ebenda, S. 1.

106 BAB, DQ 2/63, Entwurf der Juristischen Abt. vom 17.6. 1947.

107 Ebenda, III. Entwurf der Abt. I b vom 9. 7. 1947.

$108 \mathrm{BAB}, \mathrm{DQ} 2 / 261, \mathrm{Bl} .49$ f., Juristische Abt. am 17. 7.1947 an Abt. I b.

$109 \mathrm{BAB}, \mathrm{DQ} 2 / 1737, \mathrm{Bl}$. 76f., Aktennotiz der DVAS-Abt. I b vom 12. 5. 1947. Die darin enthaltenen Informationen stammten offenbar aus dem Mitteilungsblatt des Arbeitsministeriums von Nordrhein-Westfalen vom 15.4. 1947. 
derschlug. Früher als in der SBZ waren daher die Arbeitsämter in der britischen Zone dazu übergegangen, das Prinzip der Freiwilligkeit bei der Stellenvermittlung anzustreben. Generell blieb aber auch hier der quantitative Umfang der Arbeitsverpflichtungen unmittelbar von der britischen Militärbehörde abhängig, die rasch die Erfolglosigkeit der Dienstverpflichtungen erkannte: So kehrten beim Ruhrkohlenbergbau rund 73 Prozent der eingewiesenen Bergarbeiter im Monatsdurchschnitt 1946 wieder zurück ${ }^{110}$. Der Landtag von Württemberg-Baden debattierte im Frühjahr 1947 über ein Arbeitsverpflichtungsgesetz ${ }^{111}$. Ein gravierender Unterschied zur arbeitsrechtlichen Lage in der SBZ bestand aber darin, daß der Gesetzentwurf vom 1. August 1947 eine zeitliche Begrenzung bis zum 31. Dezember 1948 vorsah $^{112}$. Der hessische Landtag verabschiedete wiederum am 26. Juni 1947 ein Arbeitspflichtgesetz, das nach Intervention des amerikanischen Militärgouverneurs General Lucius D. Clay erst am 19. August in Kraft treten konnte ${ }^{113}$. Entsprechende Pläne für ein einheitliches Zonengesetz waren aber zuvor im Länderrat der amerikanischen Besatzungszone am anhaltenden Widerspruch Bayerns gescheitert ${ }^{114}$.

Parallel zur Ausarbeitung einer Verordnung zur Regelung der Arbeitseinweisungen entwickelte sich im Laufe des Sommers 1947 eine neue Debatte, nämlich über die Einrichtung eines sogenannten Dringlichkeitsausschusses. Beide Verfahren hingen inhaltlich eng zusammen, verliefen aber über einen längeren Zeitraum getrennt voneinander und fanden erst 1948 unter dem Dach einer einzigen Verordnung zusammen 115 . Der Auslöser für das neue Aufgabenfeld der DVAS - auch hier war wieder die Abteilung I $b$ federführend tätig - war der bereits erwähnte SMAD-Befehl Nr. 153 vom 29. November 1945, der die Bereitstellung von Arbeitskräften für die als wichtig erachteten Wirtschaftszweige gewährleisten wollte. Dazu war letztlich die Aufstellung einer Prioritätenliste notwendig. Diesem Zweck sollte offensichtlich die geplante Errichtung eines „deutschen Dringlichkeitsausschusses" bei der DVAS und den Landesämtern für Arbeit und Sozialfürsorge dienen. Erst am 12. Juli 1947 legte die DVAS einen ersten Entwurf vor, der einen sehr provisorischen Charakter hatte ${ }^{16}$. Dieser Ausschuß sollte sich aus jeweils einem Vertreter des Landesarbeitsamtes, des zuständigen Landesministeriums oder der Zentralverwaltung, des FDGB, der „öffentlichen Körperschaften“

110 Abelshauser, Der Ruhrkohlenbergbau, S. 30.

111 Vgl. Entwurf eines Arbeitsverpflichtungsgesetzes vom 29.5. 1947. Eine Kopie befindet sich in: ThHStA, Land Thüringen, Ministerium für Wirtschaft und Arbeit, Bd. 3694, Bl. $64 \mathrm{f}$.

112 Vgl. Entwurf eines Arbeitsverpflichtungsgesetzes nach den Beschlüssen der 3. Beratung im Landtag von Württemberg-Baden. Eine Kopie befindet sich in: ThHStA, Land Thüringen, Ministerium für Wirtschaft und Arbeit, Bd. 3694, Bl. $80 \mathrm{f}$.

113 Mai, Der Alliierte Kontrollrat, S. 382, Anm. 318.

$11+$ Ebenda.

115 Daneben liefen noch Planungen für dic Ausarbeitung einer Verordnung über die Verhängung von Ordnungsstrafen sowie einer Verordnung über die Zahlung von Trennungsgeld und Härteausgleich. Auch diese Vorarbeiten, auf die an dieser Stelle nicht näher eingegangen werden muß, da sie keinen unmittelbaren Einfluß auf die Verrechtlichung der Arbeitseinweisung hatten, flossen letztlich in die Verordnung über die Sicherung und den Schutz der Rechte bei Einweisungen von Arbeitskräften vom 2.6.1948 ein.

116 BAB, DQ 2/2077. Der Berliner Magistrat hatte bereits am 9. 7. 1945 eine Anordnung zur Sicherung des Bedarfs an Arbeitskräften für lebenswichtige Aufgaben beschlossen, die solche Dringlichkeitsstufen vorsah, in: SAPMO, NY 4182/1158, Bl. 45-47, hier BI. 47. 
sowie der Wirtschaft zusammensetzen. Die Eingruppierung in eine der sechs Dringlichkeitsstufen ${ }^{117}$ mußte beim zuständigen Landesamt zunächst beantragt werden; die Einordnung bzw. „Genehmigung einer Dringlichkeit“ sollte sich auf eine feste Anzahl von Arbeitskräften beschränken und galt offenbar nur für drei Monate. Die Landesverwaltungen konnten jedoch die endgültige Fertigstellung des Gesetzestextes nicht abwarten, sondern mußten sofort handeln, da die zahlreichen Arbeitskräfteanforderungen von seiten der sowjetischen Besatzungsmacht zu erfüllen waren. Dabei ergaben sich zwangsläufig inhaltliche Unterschiede. So enthielt etwa die Rundverfügung des thüringischen Ministeriums für Wirtschaft, Arbeit und Verkehr vom 7. August nur drei Dringlichkeitsstufen ${ }^{118}$. Am 16. August legte die DVAS einen erheblich überarbeiteten Entwurf vor, der Aufbau und Funktion des Ausschusses festlegte ${ }^{119}$. Dieser sollte nur bei der DVAS gebildet werden und sich aus jeweils einem Vertreter der SMAD, DVAS, Deutschen Zentralverwaltung für Industrie, Deutschen Zentralverwaltung für Brennstoffindustrie, Deutschen Zentralverwaltung für Verkehr, Deutschen Verwaltung für Landund Forstwirtschaft und des FDGB zusammensetzen. Mit der Durchführung und Überwachung aller erforderlichen Maßnahmen wurden sogenannte Planungsstellen beauftragt, die bei der DVAS, den Landesämtern und den Arbeitsämtern zu bilden waren. Der Referentenentwurf sah außerdem fünf Dringlichkeitsstufen vor ${ }^{120}$.

Der bisherige Diskussionsverlauf über die Bildung von Dringlichkeitsstufen hatte zu einer erheblichen Differenzierung geführt. Während anfangs eine Rangfolge der einzelnen Wirtschaftsbereiche vorgenommen worden war, ging die DVAS immer mehr dazu über, einzelne Berufsgruppen in das abgestufte System einzuordnen. Damit ergaben sich wieder Konfliktfelder mit den Landesverwaltungen, die in die Diskussion mit einbezogen worden waren ${ }^{121}$. Zwar unternahm die DVAS Ende September 1947 noch einen Anlauf und legte eine Dienstanweisung „über die Koordinierung der Arbeitskräfteanforderungen zum Zwecke der zweckmäßigen Vermittlung " aus ${ }^{122}$. Kurz darauf erhielt die Dienstanweisung die Überschrift „über die Organisierung der zweckmäßigsten Vermittlung von Arbeitskräften"123. Dieser Entwurf wies große Ähnlichkeiten mit der Anweisung zur Errichtung eines Dringlichkeitsausschusses auf. Obwohl die DVAS den Ent-

117 In ihrer Reihenfolge: 1) Unternehmen, die für die sowjetische Besatzungsmacht tätig waren; 2) Brennstoffindustrie; 3) Elektrizitätswerke; 4) Betriebe, die landwirtschaftliches Inventar herstellten; 5) Eisenbahntransportwesen; 6) Wohnungsbau und kommunale Unternehmen. Vgl. BAB, DQ 2/2077, I. Entwurf der DVAS vom 12. 7. 1947 zur Errichtung eines Dringlichkeitsausschusses. 118 ThHStA, Land Thüringen, Ministerium für Wirtschaft und Arbeit, Bd. 3597, Bl. 159.

119 BAB, DQ 2/2077.

120 1) Anforderungen der sowjetischen Besatzungsmacht sowie Katastropheneinsatz; 2) Anforderungen für Bergbau und Brennstoffindustrie sowie für „lebenswichtige“ Betriebe; 3) Textil-, Bekleidungs-, Schuh-, Metall- und Bauindustrie; 4) Haushaltswaren-, Gebrauchsartikelindustrie; 5) Gaststättengewerbe, häusliche Dienste, Theater und Musik. Vgl. ebenda, $\$ 9$.

121 Vgl. ThHStA, Land Thüringen, Ministerium für Wirtschaft und Arbeit, Bd. 3700, Bl. 475-477, Niederschrift über die Konferenz der Direktoren und Einsatzleiter der Ämter für Arbeit und Sozialfürsorge am 8.9. 1947; ThHStA, Land Thüringen, Ministerium für Wirtschaft und Arbeit, Bd. 3597, Bl. 38-42, Ministerium für Wirtschaft, Arbeit und Verkehr des Landes Thüringen am 10. 9.1947 an die SMATh.

$122 \mathrm{BAB}, \mathrm{DQ}$ 2/2077, Referentenentwurf der DVAS (Abt. I b) vom 22. 9. 1947.

123 ThHStA, Land Thüringen, Ministerium für Wirtschaft und Arbeit, Bd. 3597, Bl. 49-52, I. Entwurf der DVAS (Abt. I b) vom 23.9. 1947. 
wurf nochmals überarbeitete 124 , konnte eine Einigung in dieser Frage letztlich nicht erzielt werden. Die DVAS mußte zunächst einmal darauf verzichten, eine allgemein verbindliche Anordnung zu erlassen. Somit blieb die Frage der Bildung von Dringlichkeitsstufen im Herbst 1947 immer noch ungelöst. Nach Auffassung des thüringischen Landesamtes für Arbeit waren die Dringlichkeitsstufen leicht durchlässig: So konnten sich etwa Unternehmer darum bemühen, für ihren Arbeitskräftebedarf einen sowjetischen Befehl zu erwirken und in die oberste Dringlichkeitsstufe eingeordnet zu werden ${ }^{125}$. Der Verteilungskampf um knappe Ressourcen, in diesem Fall um Arbeitskräfte, verlagerte sich auf diese Weise nur auf eine andere Ebene.

Gleichzeitig war es der DVAS nicht gelungen, die interne Auseinandersetzung über den Verordnungsentwurf zur Regelung der Arbeitseinweisungen zu beenden. Zwar legte die Abteilung I b am 21. Juli 1947 einen erneuten Entwurf vor ${ }^{126}$. Dieser fand aber wieder nicht die Zustimmung der Juristischen Abteilung: Wichtige Vorschläge seien ohne Begründung nicht aufgenommen worden ${ }^{127}$. Aus Sicht der Juristischen Abteilung war eine Klärung und Einigung nicht mehr möglich. Der Abteilung I $b$ wurde vorgeworfen, sie habe auch in ihrem letzten Entwurf die Aufnahme einer gesetzlichen Regelung unterlassen, „in der eine Zwangsanordnung an einen Arbeitgeber, eine bestimmte Person zu beschäftigen, enthalten ist" 128 . Die Abteilung I b wies diese Kritik am 5. August weit von sich und setzte sich ausführlich mit dem Vorschlag auseinander, bei den Zwangsmaßnahmen auch die Arbeitgeber einzubeziehen ${ }^{129}$. Dies sei nicht erforderlich, da sowohl der SMAD-Befehl Nr. 153 als auch der Kontrollratsbefehl Nr. 3 den Arbeitsämtern die Einweisung von Arbeitskräften übertragen habe. Insofern war die Entscheidungsfreiheit der Unternehmer in dieser Hinsicht bereits frühzeitig eingeschränkt worden. Ferner berief sich die Abteilung I $b$ auf die Deutsche Zentralverwaltung der Industrie, die auf die Wahrung des Produktionsinteresses aufmerksam gemacht habe ${ }^{130}$. Ein Betrieb müsse die berufliche Qualifikation eines zugewiesenen Arbeitnehmers prüfen und notfalls eine Anstellung auch ablehnen können. Bei der Vorlage des nächsten Verordnungsentwurfes kam die Abteilung I b der Juristischen Abteilung etwas entgegen und nahm die "Opfer des Faschismus" in die Gruppe derjenigen auf, die der Verordnung und damit der Arbeitseinweisung nicht unterlagen ${ }^{131}$.

Meinungsverschiedenheiten traten auch zwischen der Juristischen Abteilung der DVAS und einzelnen Landesregierungen auf. Der Minister für Arbeit und Sozialpolitik von Sachsen-Anhalt hatte sich dafür ausgesprochen, im Verordnungsentwurf stärker den Weisungscharakter der SMAD zum Ausdruck zu bringen: Die Rechtsquelle solle „zweifellos eine Weisung der sowjetischen Besatzungs-

$124 \mathrm{BAB}, \mathrm{DQ}$ 2/261, Bl. 84-88, 2. Entwurf der DVAS (Abt. I b) vom 6. 10. 1947.

$125 \mathrm{BAB}, \mathrm{DQ} 2 / 2077$, Aktenvermerk der Abt. I b (Kreil) vom 28. 11. 1947.

126 BAB, DQ 2/261, B1. 54-61.

127 Ebenda, Bl. 51-53, Juristische Abt. am 24. 7. 1947 an Abt. I b.

128 Ebenda, Bl. 51.

t29 BAB, DQ 2/261, Bl. 62-64, Abt. I b am 5. 8. 1947 an Juristische Abt.

$130 \mathrm{Vgl}$. ebenda, B1. 62.

$131 \mathrm{BAB}, \mathrm{DQ}$ 2/261, Bl. 65-68, Entwurf der Abt. I b vom 7. 8. 1947. 
macht sein"132. Diesen Vorstoß kritisierte wiederum die Juristische Abteilung, die eine Einschränkung der Befugnisse der DVAS kategorisch ablehnte ${ }^{133}$.

Die CDU stimmte Arbeitseinweisungen nur in Ausnahmefällen zu und sprach sich dafür aus, in einer entsprechenden Verordnung den Betroffenen die „notwendige Rechtssicherung“ zu geben ${ }^{134}$. Arbeitseinweisungen waren nach Ansicht der CDU nur für eine „vorübergehende Periode eines Notstandes zu rechtfertigen.“ Eine zeitliche Befristung der geplanten Verordnung auf zwei Jahre wurde daher gefordert. Dieser Standpunkt fand sich auch im Wirtschafts- und Sozialprogramm der CDU wieder. Grundsätzlich zog man dort die freiwillige Arbeitsvermittlung der Arbeitseinweisung vor, die „zur Zeit noch unvermeidlich“ sei ${ }^{135}$.

Anfang September 1947 näherten sich die konträren Positionen der beiden DVAS-Abteilungen weiter an. Am 4. September hatte die Abteilung I b einen weiteren überarbeiteten Entwurf präsentiert ${ }^{136}$, an dem die Juristische Abteilung nur wenig auszusetzen hatte ${ }^{137}$. Nach abschließenden redaktionellen Arbeiten konnte die Abteilung I b am 11. September die vorläufig letzte Fassung der geplanten Verordnung „über die Regelung von Arbeitseinweisungen in der sowjetischen Besatzungszone" vorlegen ${ }^{138}$. Letztlich war es der Juristischen Abteilung gelungen, sich in einigen Fragen gegenüber der Abteilung I b doch noch durchzusetzen. Insgesamt gesehen überwog aber der Eindruck eines Kompromisses.

Bei den Arbeitstreffen von Vertretern der Landesarbeitsämter, der zuständigen Landesministerien sowie der Berliner Zentralverwaltung war das Thema Arbeitseinweisung von zentraler Bedeutung. Eine Analyse der überlieferten Tagungsberichte in der zweiten Hälfte des Jahres 1947 vermittelt einen Einblick in die sich inhaltlich langsam wandelnde Diskussion. Auffallend ist dabei vor allem die Tatsache, daß zahlreiche Vertreter der Arbeitsverwaltung ab dem Spätsommer 1947 immer kritischer über das Instrument der Zwangsverpflichtung berichteten und einen Wechsel in der Arbeitsmarktpolitik forderten. Nachdem auch noch die SMAD den Befehl Nr. 234 veröffentlicht hatte, verstärkten sich die Stimmen auf deutscher Seite, welche die Einführung eines Anreizsystems verlangten. Die Freiwilligenwerbung sollte insgesamt die Arbeitseinweisung ablösen.

Das Ausmaß der Arbeitseinweisungen in den einzelnen Ländern hing wesentlich mit den Anforderungen der sowjetischen Besatzungsmacht zusammen. Eine besonders hohe Belastung meldete etwa das Landesarbeitsamt in Potsdam für Brandenburg im Juli 1947: Gemäß SMA-Befehl Nr. 193 mußten 4000 Arbeitskräfte für die Oderregulierung gestellt werden; im September erfolgte eine Ergänzungsauflage in Höhe von weiteren 3730 „Fachkräften“"139. Etwa zeitgleich hatte das Potsdamer Landesarbeitsamt 3000 Arbeitskräfte für das Arbeitsvorhaben Flugplatz Schönefeld zur Verfügung zu stellen. Dies waren in Brandenburg zu

$132 \mathrm{BAB}, \mathrm{DQ} 2 / 63$, Minister für Arbeit und Sozialpolitik am 19. 8. 1947 an DVAS.

133 Ebenda, Juristische Abt. am 1.9.1947 an Abt. III a.

134 ACDP, VII/011/A 533, Entschließung des 2. Unionstages zur Sozial- und Gewerkschaftspolitik (6.-8.9.1947).

135 ACDP, VII/011/906, Wirtschafts- und Sozialprogramm der CDU, S. 6 f.

136 BAB, DQ 2/261, B1. 77-81.

137 Ebenda, Bl. 76, Juristische Abteilung am 10. 9. 1947 an Abt. I b.

$138 \mathrm{BAB}, \mathrm{DQ} 2 / 2079$.

$139 \mathrm{BAB}, \mathrm{DQ} 2 / 2156$, Landesarbeitsamt Potsdam am 6. 10. 1947 an die DVAS, S. 1. 
diesem Zeitpunkt nur die beiden größten Projekte mit Arbeitskräfteanforderungen. Daneben gaben sowohl die SMA der Länder als auch die örtlichen Kommandanturen Auflagen an die Arbeitsämter weiter. Im Ländervergleich lag Brandenburg Mitte 1947 vermutlich an der Spitze ${ }^{140}$. Vor allem die zahlenmäßig hohen Anforderungen von seiten der sowjetischen Besatzungsmacht waren nur durch den Einsatz mehrerer Kreisverwaltungen zu erfüllen. Es sei aber - so das Potsdamer Landesarbeitsamt - ,ein Unding, annehmen zu wollen, daß diese vielen Tausend Arbeitskräfte sich freiwillig in die primitiveren Lebensverhältnisse an der Oder begeben hätten" 141 . Wolle man zur Freiwilligenmeldung übergehen, müsse vielmehr „ein besonderer Anreiz“ gegeben sein. Mit Rücksicht auf die Bevölkerung plädierte das Landesarbeitsamt für eine Abkehr von der Arbeitseinweisung: „Die Aversion der Bevölkerung gegen die Oderarbeiten erhellt am besten die Tatsache des Abwanderns von rd. 1000 Frankfurter Einwohnern, die an sich ja noch den Vorteil hatten, trotz der Einweisung in ihrer Heimatstadt wohnen zu können." Die Landesverwaltungen konnten offensichtlich ihren Handlungsspielraum auch nutzen, um diesen drohenden sozialen Konflikt vorbeugend zu entschärfen. So schloß das Landesarbeitsamt in Potsdam Verträge mit den Baustäben an der Oder ab, welche gewisse Verbesserungen bei der Versorgung mit Bekleidung oder mit warmen Mahlzeiten vorsahen. Dieser Handlungsspielraum hing von der sowjetischen Zustimmung und der finanziellen Ausstattung ab. Es kann aber festgehalten werden, daß bei der arbeitsintensiven Oderregulierung bereits im Spätsommer 1947 ein Wechsel der arbeitsmarktpolitischen Instrumente eingesetzt hatte. Die Umsetzung dieser Politik erfolgte allerdings nicht schlagartig und Arbeitseinweisungen blieben prinzipiell auch nicht ausgeschlossen. Das Landesarbeitsamt war jedoch der Ansicht, auf diesem Wege das Zwangsmittel der Einweisung in Arbeit "auf ein Mindestmaß" reduzieren zu können"142.

Der Politikwechsel von der Zwangseinweisung zur Freiwilligenwerbung hatte auch Folgen für die arbeitsrechtliche Diskussion, die zunächst einmal unterbrochen wurde. Von enormer Bedeutung war in diesem Zusammenhang - darauf ist bereits aufmerksam gemacht worden - der SMAD-Befehl Nr. 234. Dieser hatte sogar die Überprüfung und Bestätigung einer „Instruktion über die Regelung der Arbeitsbeschaffung und der Verteilung der Arbeitskräfte" angeordnet ${ }^{143}$. Die DVAS versuchte Ende Oktober die geplante Verordnung dem Paradigmenwechsel anzugleichen und arbeitete eine Anweisung zum „Verfahren des Arbeitseinsatzes und der Verteilung der Arbeitskräfte" aus ${ }^{144}$. Die SMAD signalisierte ihre grundsätzliche Zustimmung zum Entwurf, behielt sich aber eine Einzelprüfung noch vor ${ }^{145}$. Der Anweisungsentwurf versuchte die Arbeitsvermittlung und -einweisung umfassend zu regeln. Er enthielt unter anderem Bestimmungen zur Ver-

\footnotetext{
140 Sachsen-Anhalt registrierte im August 1947 insgesamt 4591 Zwangseinweisungen. Damit lag der Anteil im Vergleich zu den Arbeitsvermittlungen unter 10\%. LA Magdeburg LHA, Rep. K MW, Nr. 10148, Situationsbericht vom 10. 9. 1947.

$141 \mathrm{BAB}, \mathrm{DQ} 2 / 2156$, Landesarbeitsamt Potsdam am 6. 10. 1947 an die DVAS, S. 2.

142 Ebenda, S. 4.

${ }^{143}$ Vgl. SMAD-Befehl Nr. 234 vom 9. 10. 1947, Ziff. 13, Abschnitt a), in: Arbeit und Sozialfürsorge 3 (1948), S. 453.

$144 \mathrm{BAB}, \mathrm{DQ} 2 / 2077$.

145 Ebenda, Notiz der Abt. I B (Kreii) vom 21. 10. 1947 an Präsident Brack.
} 
teilung der Arbeitskräfte und betonte erneut die Vorrangigkeit der Freiwilligenwerbung vor der Arbeitseinweisung. Anschließend legte er drei Dringlichkeitsstufen fest, deren genaue Abgrenzung aber etwas unklar blieb. Ausführlich behandelte der Entwurf das zentrale und umstrittene Thema der Arbeitseinweisung und verband dieses inhaltlich mit Bestimmungen über Trennungsgelder, Härteausgleich sowie über das Beschwerdeverfahren. Die geplante Anweisung enthielt bis auf die von der SMAD gewünschte Reduzierung der Dringlichkeitsstufen ${ }^{146}$ wenig Neues, sondern stellte vielmehr den erstmaligen Versuch dar, die einzelnen, bisher getrennten gesetzlichen Planungen in einer Verordnung zusammenzufassen. Die SMAD war vermutlich die treibende Kraft bei der Bündelung der verschiedenen Entwürfe zu einer Anweisung; gegenüber der DVAS gab sie frühzeitig zu erkennen, daß sie Wert legte auf eine rasche Verabschiedung und Veröffentlichung in Verbindung mit dem Befehl Nr. 234147. Sowohl der FDGB als auch die DVAS brachten bei gemeinsamen Unterredungen mit SMAD-Vertretern eine ganze Reihe von Änderungsvorschlägen ein. So sollte beispielsweise die Bezeichnung „Anweisung“ in „Verordnung" geändert werden. Die Einschaltung von Arbeitsgerichten im Zuge des Beschwerdeverfahrens wurde von deutscher Seite ebenfalls kritisiert ${ }^{148}$. Darüber hinaus brachte die DVAS einige sprachliche und stilistische Verbesserungen ein, welche von der SMAD offensichtlich auch gebilligt wurden ${ }^{149}$.

Bei der weiteren Ausarbeitung der geplanten Verordnung wurde wieder die Juristische Abteilung eingeschaltet, die bereits am 3. Dezember 1947 einen überarbeiteten Entwurf vorlegte, der in erster Linie sprachliche Veränderungen enthielt ${ }^{150}$. Helmut Lehmann unterbreitete dem Zentralsekretariat eine Beschlußvorlage, in der dem Entwurf mit einzelnen Änderungen und Ergänzungen zugestimmt wurde151. Lehmann sprach sich vor allem dafür aus, Frauen mit Kindern von der Arbeitseinweisung ausdrücklich zu befreien. Mehrere SED-Landesvorstände hielten es für angebracht, die Finanzierung des Härteausgleiches nur den Unternehmern zu überlassen. Lehmann ging diese Forderung zu weit, er hielt einen Finanzierungsanteil in Höhe von 50 Prozent für "gerechtfertigt “"152. Eine Verschärfung verlangte Lehmann bei den Strafregelungen: „Wenn jemand der Arbeitseinweisung keine Folge leistet, kann der Zweck der Verordnung nicht durch eine Geldstrafe erreicht werden, sondern nur durch Einweisung in ein Arbeitslager. " ${ }^{153}$ Die Einweisung in ein Arbeitslager konnte demzufolge für eine Dauer bis zu sechs Monaten verhängt werden. Nachdem die SMAD zuvor auf eine rasche

146 SAPMO, NY 4182/1198, Bl. 7-12, hier Bl. 9, Bericht der Abt. für Wirtschaftsfragen vom 13. 11. 1947 über die 1. Sitzung des Ausschusses zur Überwachung der Maßnahmen zum Befehl Nr. 234.

147 SAPMO, DY 34, 18/e/331, Aktennotiz des FDGB (HA 3) über eine Besprechung bei der DVAS am 10. 11. 1947. Die treibende Kraft der SMAD bei der Ausarbeitung der Verordnung bleibt dagegen weitgehend unberücksichtigt bei: Thiel, Arbeitsrecht in der DDR, S. 38.

${ }_{1+8}$ SAPMO, DY 34, 18/e/331, Aktennotiz des FDGB (HA 3) über eine Besprechung bei der DVAS am 10.11. 1947.

149 BAB, DQ 2/2040, Bl. 103-105, Aktenvermerk der Abt. I b über Besprechung mit der SMAD am 11.11. 1947.

150 SAPMO, NY 4182/1158, Bl. 168-180.

${ }^{51}$ Ebenda, Bl. 165-167, Vorlage Lehmanns vom 10. 12. 1947 an das Zentralsekretariat.

152 Ebenda, Bl. 167.

153 Ebenda. 
Verabschiedung der Verordnung gedrängt hatte, nahm sie sich mit einem Male sehr viel Zeit, ohne daß die DVAS oder die SED-Führung den Grund für das geänderte Verhalten erkennen konnten ${ }^{154}$. Das Zentralsekretariat der SED befaßte sich am 22. Dezember 1947 mit dem Entwurf und erteilte den beiden Abteilungen Arbeit und Sozialfürsorge sowie Wirtschaft den Auftrag, die Fertigstellung der Verordnung aufmerksam zu verfolgen ${ }^{155}$. Vergleichsweise spät meldete sich der FDGB-Bundesvorstand Ende Dezember nochmals zu Wort und brachte seinerseits einige Änderungsvorschläge ein, die er für unabdingbar hielt156. Obwohl die Hauptabteilung Sozialpolitik zu Beginn ihres Schreibens betonte, daß „die Interessen der arbeitenden Bevölkerung, die wir ja wahrzunehmen haben, einige Änderungen notwendig machen ${ }^{157}$, bezogen sich doch die Vorschläge insgesamt nur auf zusätzliche Erläuterungen oder Ergänzungen, die inhaltlich keinen Dissens erkennen ließen. Bei den Trennungsgeldern plädierte der FDGB-Bundesvorstand für eine Erhöhung von 2,50 RM auf $3 \mathrm{RM}$.

Bei Besprechungen zwischen Vertretern der DVAS und der SMAD konnte über den Wortlaut der Verordnung auch Ende Dezember 1947 noch keine endgültige Einigung erzielt werden. Als offene Fragen erwiesen sich in erster Linie zwei Paragraphen, zum einen der Härteausgleich und zum anderen die Strafbestimmungen. Nach Ansicht der SMAD, die ausdrücklich für eine Einschränkung der Arbeitseinweisung eintrat, sollten die Betriebe den Härteausgleich alleine tragen ${ }^{158}$. Dagegen machte der DVAS-Mitarbeiter Kreil geltend, man dürfe nicht verkennen, daß damit die unternehmerische Kalkulation "erheblichen Störungen ausgesetzt sei, da er ja nie wissen kann, wie hoch der Prozentsatz der Arbeitskräfte sei, die ihm von außerhalb zugewiesen werden und wie hoch die Summe des Härteausgleiches sei, die auf das Produkt einkalkuliert werden müßte." Unbeeindruckt reagierte der SMAD-Vertreter Schaposchnikow und erklärte, „daß Unternehmer, die nicht konkurrenzfähig sind, verschwinden müssen." Durch die Aufbürdung der Einweisungskosten auf den Unternehmer werde - so die Mutmaßung Schaposchnikows - dieser veranlaßt, seinen Betrieb zu überprüfen, „ob nicht doch durch Organisationsmaßnahmen innerhalb des Betriebes Arbeitskräfte eingespart oder durch technische Verbesserungen die Arbeitsleistungen gesteigert werden können." $\mathrm{Da}$ ein Kompromiß nicht gefunden werden konnte, sprach sich Kreil für eine nochmalige "reifliche“ Überprüfung auch von seiten der DVAS aus. Der zweite Streitpunkt drehte sich um die Frage, wem die Aufgabe der Bestrafung zufallen sollte. Während der SMAD-Vertreter die Auffassung vertrat, die Befugnisse ordentlichen Gerichten und nicht den Arbeitsämtern zu übertragen, verwies Kreil darauf, daß auf diese Weise die Arbeitskräftelenkung „sehr erschwert“ würde ${ }^{159}$. Gerade die Tatsache, daß die Arbeitsämter über diese Sanktionsmöglichkeit in der Vergangenheit nicht verfügt hätten, ,hätte den böswilligen Arbeitsbummelanten die Gewißheit gegeben, daß Strafverfahren bis zu ihrer Erledigung sehr lange Zeit

154 BAB, DQ 2/2040, Bl. 109, Niederschrift über die Besprechung mit der SMAD am 4. 12. 1947.

155 SAPMO, DY 30/IV 2/2.1/159.

156 BAB, DQ 2/2077, FDGB-Bundesvorstand (HA 3) am 29. 12. 1947 an die DVAS.

157 Ebenda, S. 1.

158 BAB, DQ 2/1711, Niederschrift der DVAS (Abt. I b) über Besprechung mit der SMAD am 31. 12. 1947 in Karlshorst, S. 2 f.

159 Ebenda, S. 4. 
benötigen und sie infolgedessen diese nicht zu befürchten brauchten“, so Kreil weiter. Offenbar hatte die SMAD in diesem Punkte ihre bisherige Meinung vollständig geändert; auch hier waren weitere Verhandlungen erforderlich.

Im Oktober 1947 konnte zumindest mit der SMAD in Karlshorst Einigkeit darüber erzielt werden, daß bei zwei Befehlen gleicher Dringlichkeit "den in Frage kommenden Kräften die Entscheidung freisteht, sich freiwillig für das eine oder andere Arbeitsvorhaben zu entscheiden oder sich nach dem Ermessen des Arbeitsamtes einweisen zu lassen"160. Damit sollten zeitraubende Konflikte zwischen der deutschen Arbeitsverwaltung und den Organen der sowjetischen Besatzungsmacht vermieden werden. Erst Anfang des nächsten Jahres brachten die Landesämter „beachtliche grundsätzliche Bedenken“ gegen die Einteilung der nunmehr drei Dringlichkeitsstufen vor ${ }^{161}$. Ihre Vorbehalte richteten sich dagegen, daß die einzelnen Gruppen nicht nach Wirtschaftszweigen aufgebaut, sondern von den Entscheidungen der sowjetischen Besatzungsmacht sowie der DVAS abhängig sein sollten. Auch in diesem Punkte mußte die DVAS Nachverhandlungen mit der SMAD aufnehmen. Der Vorschlag der DVAS wenige Tage später stellte einen Kompromiß dar: Während in der ersten Stufe Anforderungen der SMAD und der DVAS aufgeführt wurden, sahen die beiden anderen Stufen primär eine Auflistung von einzelnen Wirtschaftszweigen vor ${ }^{162}$.

Das Umdenken bei der Arbeitsverwaltung - weg von der Arbeitsverpflichtung und hin zur Anwerbung - wurde erheblich beeinflußt durch die Situation im Uranbergbau. An dieser Stelle sei nur kurz der größere Zusammenhang angedeutet ${ }^{163}$ : Hier konnten die stellenweise hohen Arbeitskräfteforderungen nur durch Einweisungen erfüllt werden. Die katastrophale soziale Lage im sächsischen und thüringischen Erzbergbau schien einen Instrumentenwechsel bei der Rekrutierung von Arbeitskräften zu verlangen ${ }^{164}$. Allerdings wurde auf das Mittel der Arbeitseinweisung nicht grundsätzlich verzichtet. Die DVAS forderte die Länder auf, bei der Erfüllung ihrer Kontingente für den Uranbergbau „möglichst durch Anwerbung" Freiwillige zu gewinnen und nur im Notfall auf Arbeitsverpflichtungen zurückzugreifen ${ }^{165}$. Am Rande sei darauf hingewiesen, daß eine wichtige Voraussetzung für die Aufnahme neuer Arbeitskräfte die Lösung der Unterbringungsfrage in den Kreisen war, die von Anfang an nicht befriedigend gelöst werden konnte. Der Wohnraumbedarf blieb gerade in den ersten Nachkriegsjahren oftmals ungedeckt, vor allem in den Gebieten mit Großprojekten wie der Oderregulierung und dem Uranbergbau im Erzgebirge.

Anfang des Jahres 1948 setzte die DVAS die Debatte über die Verordnung fort. Dabei schalteten sich auch die Vertreter der Länder wieder ein, die vor allem bei der Formulierung der Bestimmungen, welche die Finanzierung des Härteaus-

160 BAB, DQ 2/1891, Bl. 23-32, hier Bl. 32, Bericht über die Konferenz der Arbeitsminister der Länder am 20./21.10. 1947 in Berlin.

161 BAB, DQ 2/2077, Fernspruch von Kreil (DVAS-Abt. I b) an Schaposchnikow am 12. 1. 1948.

162 Ebenda, Vorschlag der DVAS (Abt. I b) vom 15.1.1948.

163 Vgl. dazu Kap. I.4. (Arbeitskräfte für den Uranbergbau im Erzgebirge).

164 Vgl. Karlsch, Allein bezahlt?, S. 136-146; Roeling, Arbeiter im Uranbergbau.

165 BAB, DQ 2/1537, Niederschrift über den Verlauf der Arbeitstagung der DVAS am 6./7. 1. 1948 in Leipzig, S. 9. 
gleichs regeln sollten, ihre Einwände vorbrachten ${ }^{166}$. Nach einer Aussprache am 6. Januar 1948 einigten sich Vertreter der DVAS und der Länder darauf, daß „80\% aus öffentlichen Mitteln und 20\% vom Unternehmer zu tragen sind " 167 . Auf dieser Basis sollten die Verhandlungen mit der SMAD wieder aufgenommen werden. Die DVAS stimmte außerdem dem Vorschlag einzelner Ländervertreter zu, den Härteausgleich nur für ein halbes Jahr auszahlen zu lassen. Gleichzeitig waren die Länder, aber auch die DVAS einverstanden mit der Forderung der SMAD, den Arbeitsämtern das Ordnungsstrafrecht nicht zu übertragen. Als Voraussetzung wurde allerdings die Einrichtung von „Schnellgerichten“ gefordert, die „eine sofortige Bestrafung ermöglichen" sollten ${ }^{168}$. Auf Anweisung der sowjetischen Besatzungsmacht durften zunächst jedoch die Beratungen auf deutscher Seite nicht weitergeführt werden. Vermutlich wollte die SMAD und ihre Abteilung Arbeitskraft die bei den Verhandlungen aufgetretenen Fragen intern klären und mit einem einheitlichen Meinungsbild wieder in die Beratungen mit der DVAS gehen. Die geplante Verordnung über das Verfahren der Arbeitsvermittlung und der Verteilung der Arbeitskräfte wurde im übrigen von einzelnen Ländervertretern ausdrücklich begrüßt. So äußerte etwa der Mitarbeiter des thüringischen Ministeriums für Arbeit und Sozialwesen, Oberregierungsrat Studzinski, die Hoffnung, daß die Einführung der Dringlichkeitsstufen den einzelnen Ortskommandanten die Möglichkeit nehmen werde, in den Vermittlungsprozeß direkt eingreifen zu können. Die Zurückdrängung dieser Einflußnahme und die einheitliche Kontrolle durch die Arbeitsverwaltung treffe aber auch die Betriebe: Diese könnten „nun nicht mehr zu den Ortskommandanten laufen, um Befehle zur Gestellung von Arbeitskräften durch die Arbeitsämter zu erwirken" 169 .

Mitte Februar 1948 waren die Arbeiten an der Verordnung über das Verfahren der Arbeitsvermittlung und die Verteilung der Arbeitskräfte bereits sehr weit gediehen. So stellte die Juristische Abteilung zusammen mit der Abteilung I b der DVAS fest, daß der Entwurf „im Gesamtergebnis einen sehr beachtlichen Fortschritt" gebracht habe ${ }^{170}$. Die DVAS-Abteilung vermittelte den Eindruck, als ob der Verordnungsentwurf nur noch redaktionell bearbeitet zu werden brauchte. Gespräche mit Vertretern der Abteilung Arbeitskraft erbrachten zu diesem Zeitpunkt nur noch eine Ergänzung des Paragraphen 24 der geplanten Verordnung: Dabei ging es konkret um die Ausweitung der Fälle, bei denen eine Arbeitseinweisung nicht erfolgen durfte ${ }^{171}$. Die DVAS konnte die SMAD von der Notwendigkeit dieser Ergänzung überzeugen und wurde auch in dieser Angelegenheit vom FDGB-Bundesvorstand unterstütz ${ }^{172}$. Die nochmals überarbeitete Verordnung bestätigte der Chef des Stabes der Sowjetischen Militärverwaltung, Generalleut-

166 Ebenda, Niederschrift über den Verlauf der Arbeitstagung der DVAS (Abt. I b) am 6./7. 1. 1948 in Leipzig.

16) Ebenda, S. 4.

168 BAB, DQ 2/137, Bl. 204-206, hier Bl. 204, Niederschrift über den Verlauf der Arbeitstagung der DVAS (Abt. I b) am 6./7.1. 1948 in Leipzig.

169 BAB, DQ 2/2062, Protokoll der 2. Sitzung der Arbeitstagung am 6./7.1. 1948 in Leipzig, S. 1. Zu dieser Tagung existieren einige, in unterschiedlicher Ausführlichkeit gehaltene Protokolle.

$170 \mathrm{BAB}, \mathrm{DQ} 2 / 154, \mathrm{Bl}$. 4, Juristische Abt. am 14. 2. 1948 an Präsident Brack.

171 BAB, DQ 2/1082, Aktenvermerk Bracks vom 14. 2. 1948.

172 SAPMO, DY 34/20149, FDGB-Bundesvorstand (HA 3) am 14. 2. 1948 an die SMAD-Abteilung Arbeitskraft (Schaposchnikow). 
nant G. Lukjantschenko, bereits am 24. Februar $1948^{173}$. Gleichzeitig begannen der FDGB-Bundesvorstand und die HVAS-Leitung mit Vorarbeiten zu einer Durchführungsbestimmung, in der das Verfahren vor den Beschwerdeausschüssen genau geregelt werden sollte ${ }^{174}$. In den Gesprächen zwischen den an der Ausarbeitung beteiligten deutschen Stellen drehte es sich vor allem um die Zusammensetzung der Ausschüsse. Unterschiedliche Ansichten bestanden bei der Frage, wer als juristischer Vertreter vor den Ausschüssen noch zugelassen werden konnte. Während die Juristische Abteilung der HVAS dafür plädierte, Rechtsanwälte auch in solchen Verfahren prinzipiell zuzulassen, sprach sich der FDGBBundesvorstand eindeutig dagegen aus. So betonte auch die Hauptabteilung 6 (Arbeitsrecht) beim FDGB-Bundesvorstand, daß Rechtsanwälte vor den Beschwerdeausschüssen „nichts zu suchen [haben], abgesehen davon, daß bei dem Mangel an Anwälten wohl kaum ein Anwalt sich dazu hergibt, derartige Streitfälle [...] überhaupt zu vertreten“"175. Der von der HVAS-Abteilung I b vorgelegte Entwurf einer Dienstanweisung enthielt jedoch nur präzisierende Angaben zum ersten Abschnitt der geplanten Verordnung und beschränkte sich daher auf die Einstufung in die Dringlichkeitsstufen, die Durchführung der Arbeitsvermittlung sowie die Regelung der monatlichen Meldungen ${ }^{176}$. In einer weiteren Durchführungsbestimmung sollte offenbar das Verfahren vor den Beschwerdeausschüssen festgeschrieben werden. Hierzu gab es wiederum Besprechungen zwischen Vertretern der HVAS und des FDGB-Bundesvorstandes. Anfang April 1948 bestand dann Einmütigkeit darüber, daß sich dieser Ausschuß aus nicht mehr als drei Personen zusammensetzen sollte ${ }^{177}$.

Insgesamt gesehen muß festgehalten werden, daß die Diskussion über die Intensivierung der Arbeitskräfteanwerbung und der damit verbundenen Zurückdrängung der Arbeitsverpflichtung die Ausarbeitung einer grundlegenden Verordnung zunächst einmal ins Stocken brachte. Auf der Arbeitstagung der HVAS am 27./28. April 1948 in Erfurt machte der SMAD-Vertreter Schaposchnikow deutlich, daß der „Sinn der Verordnung ist, von den Arbeitseinweisungen abzukommen und einen zweckmäßigen Arbeitseinsatz zu garantieren“178. Die Notwendigkeit der Zuweisungen sei „genauestens“ zu überprüfen; für einen „besonderen Schutz der Rechte der Arbeiter“ müsse gesorgt werden. Darüber hinaus sei - so Schaposchnikow weiter - die Trennungsentschädigung zu garantieren und ein Lohnausgleich einzuführen, „wenn eine Differenz zwischen dem Lohn der alten und der neuen Arbeitsstelle besteht." Die HVAS kam diesem sowjetischen Anliegen nach und legte noch im Mai 1948 einen sprachlich veränderten Verordnungsentwurf vor, der als Anlage zum SMAD-Befehl Nr. 234 geführt wurde und die neue Bezeichnung hatte: Verordnung „über die Sicherung und den Schutz der

173 BAB, DQ 2/261, Bl. 148-154.

174 SAPMO, DY 34/20149, FDGB-Hausmitteilung vom 15. 3. 1948.

175 Ebenda, Hausmitteilung von HA 6 für HA 3 vom 23. 3. 1948.

176 BAB, DQ 2/111, Bl. 98-108, Dienstanweisung (Entwurf) der HVAS (Abt. I b) vom 31. 3. 1948.

17) SAPMO, DY 34/20149, Aktennotiz der HA 3 des FDGB-Bundesvorstandes über eine Besprechung mit Donau und Krüger am 2.4. 1948.

178 BAB, DQ 2/1711, Niederschrift über den Verlauf der am 27./28. 4. 1948 stattgefundenen Arbeitstagung der HVAS (Abt. I b) in Erfurt, S. $4 \mathrm{f}$. 
Rechte für Arbeiter und Angestellte bei Arbeitseinweisungen"179. Die Akzentverschiebung war nicht zu übersehen. Allerdings hatte sich schon 1947 angedeutet, $\mathrm{da} ß$ die Arbeitseinweisung in weitgehend geordnete Bahnen gelenkt werden sollte. Dazu waren Ausnahmeregelungen und Einspruchsmöglichkeiten geschaffen worden. Bereits Paragraph 1 des neu erstellten Entwurfes legte fest, daß die Versorgung mit Arbeitskräften „in der Regel auf dem Wege der Werbung freiwilliger Arbeitskräfte" zu erfolgen habe. Arbeitseinweisung war demzufolge nur erlaubt, wenn auf andere Weise der Bedarf nicht zu decken war. Allerdings war der Katalog der Arbeiten, bei denen dieses Zwangsmittel eingesetzt werden konnte, relativ unscharf gefaßt und ließ den Arbeitsämtern große Interpretationsspielräume: Dazu zählten die Beseitigung von „öffentlichen Notständen sowie von Unfall- und Katastrophenfolgen“", die Erfüllung von Produktionsprogrammen "in lebenswichtigen“ Industrie- und Wirtschaftszweigen sowie die Erledigung von „Aufgaben der Besatzungsmächte" ${ }^{180}$. Gleichzeitig führte der Entwurf sogenannte Dringlichkeitsstufen ein, in welche einzelne Industrie- und Wirtschaftszweige eingeordnet wurden ${ }^{181}$. Dadurch erhoffte man sich offensichtlich eine weitgehende Sicherung der Versorgung mit Arbeitskräften, die zudem in geregelten Bahnen ablaufen sollte. So gehörten zur ersten Dringlichkeitsstufe die Betriebe der Bergbau- und Hüttenindustrie sowie die Zulieferbetriebe für den Eisenbahnbau. Des weiteren fielen die Kommunalbetriebe der Wasser- und Stromversorgung in diese Gruppe. Zur zweiten Gruppe zählte vor allem die Bauund Landwirtschaft. Betriebe der Konsumgüterindustrie befanden sich dagegen in der dritten Gruppe. Die Einordnung in die einzelnen Dringlichkeitsstufen bevorzugte die Schwer- und Grundstoffindustrie, diente in erster Linie dem Aufbau einer neuen Infrastruktur und war vor allem der unmittelbaren Nachkriegszeit geschuldet. Der Verordnungsentwurf wollte jedoch nicht nur die Arbeitseinweisung, sondern auch die Arbeitsvermittlung regeln. Erneut wurde die zentrale Position der Arbeitsämter als Schalt- und Lenkungszentrale festgeschrieben. Erstmals erhielten nun aber die Arbeitsämter die Aufgabe zugewiesen, den konkreten Bedarf in den einzelnen Betrieben zu überprüfen, um eine Hortung von Arbeitskräften auszuschließen. Die Arbeitseinweisung wurde wie auch in den ersten Entwürfen auf sechs Monate begrenzt; in Ausnahmefällen war eine Verlängerung bis zu drei Monaten möglich. Die Einweisung in Arbeit wurde auf bestimmte Altersgruppen beschränkt: Männer zwischen 18 und 60 Jahren sowie Frauen zwischen 18 und 45 Jahren. Dagegen hatte sich die Gruppe derjenigen vergrößert, die von vornherein nicht herangezogen werden konnten ${ }^{182}$. Zu den bisher in den Entwürfen bereits aufgenommen Personengruppen kamen nunmehr neu hinzu: Frauen mit Säuglingen bzw. mit Kindern unter sechs Jahren sowie Frauen mit einem eigenen Haushalt. Darüber hinaus waren auch Invaliden und "Arbeitsunfähige“ von der Einweisung befreit. Wichtige Bestandteile des neuen Verordnungsentwurfes waren ferner die Bestimmungen über Trennungsgeld und sogenannten Härteaus-

174 BAB, DC 15/325, Bl. 12-19.

180 Ebenda, $\$ 3$ des Verordnungsentwurfes.

181 Ebenda, $\int 4$.

182 Ebenda, $\$ 11$ und 12. 
gleich ${ }^{183}$. Soziale Härten, die im Zuge der Arbeitseinweisung für den Betroffenen auftraten, sollten somit vermindert werden. Abschließend enthielt der Entwurf noch jeweils einen Abschnitt zum Beschwerdeverfahren sowie zu den Strafen bei Verletzung der Verordnungsbestimmungen, die im Grunde keine wesentlichen Veränderungen mit sich brachten.

Bei der weiteren Überarbeitung des Verordnungsentwurfes entfiel vor allem Paragraph 2, der die Werbung und Vermittlung von Arbeitskräften den Arbeitsämtern zugewiesen hatte ${ }^{184}$. Vermutlich sahen HVAS und DWK darin eine überflüssige Wiederholung bereits bekannter rechtlicher Bestimmungen. Das Sekretariat der DWK stimmte auf seiner Sitzung am 19. Mai 1948 dem Entwurf mit der vorgesehenen Kürzung grundsätzlich $\mathrm{zu}^{185}$. Nach einer redaktionellen Überarbeitung sollte der Entwurf anschließend von der Vollversammlung der DWK verabschiedet werden. Vor allem der FDGB ${ }^{186}$ aber auch das thüringische Ministerium für Wirtschaft ${ }^{187}$ brachten noch einige Änderungsvorschläge ein, die jedoch keine grundsätzlichen Meinungsverschiedenheiten erkennen ließen. Die Vollversammlung der DWK stimmte dem Entwurf mit einigen geringfügigen Veränderungen am 2. Juni schließlich $\mathrm{zu}^{188}$. Bei der redaktionellen Überarbeitung schaltete sich die SMAD ein. Ob erst zu diesem Zeitpunkt eine Aussprache über die geplante Verordnung in Karlshorst stattfand, kann nicht eindeutig beantwortet werden. Fest steht, daß die Abteilung Arbeitskraft Verbesserungsvorschläge einbrachte, nachdem die DWK ihren Beschluß bereits gefaßt hatte. Viele Anfragen der SMAD-Vertreter zeigten Unkenntnis und partiell auch Desinteresse. So wollte etwa Iljuschin bei einer gemeinsamen Besprechung mit dem HVAS-Mitarbeiter Krüger am 19. Juni wissen, warum in der Verordnung die Bezeichnung „Amt für Arbeit und Sozialfürsorge" gewählt worden sei ${ }^{189}$. Dabei handele es sich doch um „zwei verschiedene Ämter“. Daraufhin mußte Krüger erklären, daß dies die amtliche Bezeichnung sei. Außerdem vermißte Iljuschin eine Bestimmung, die der HVAS das Recht zur Arbeitseinweisung ausdrücklich einräumte. Nach Ansicht des HVAS-Vertreters war dieses „ein selbstverständliches Recht“, das nicht besonders hervorgehoben werden mußte. Die Verordnung wurde offiziell am 6. Juli im Zentralverordnungsblatt veröffentlicht ${ }^{190}$, nachdem der Text in Karlshorst endgültig abgesprochen worden war. Dabei wurde auch vereinbart, einige Detailfragen in einer Durchführungsbestimmung gesondert zu regeln ${ }^{191}$.

183 Ebenda, $\$ 21-27$.

184 BAB, DC 15/325, Bl. 23-30, Entwurf der HVAS vom 14. 5. 1948.

185 Ebenda, Bl. 2.

186 ThHStA, Land Thüringen, Ministerium für Wirtschaft und Arbeit, Bd. 3695, Bl. 42, Änderungsvorschläge des FDGB (o.O., o.D.).

187 ThHStA, Land Thüringen, Ministerium für Wirtschaft und Arbeit, Bd. 3695, Bl. 40 f., Ministerium für Wirtschaft (Abt. I) des Landes Thüringen am 29. 5. 1948 an Minister Willy Hüttenrauch.

188 BAB, DC 15/329, Bl. 1-4, Protokoll über die 3. ordentliche Sitzung der DWK am 2.6. 1948. Die Verordnung ist abgedruckt in: Arbeit und Sozialfürsorge 3 (1948), S. 220-222.

$189 \mathrm{BAB}, \mathrm{DQ} 2 / 261$, Bl. 242-245, hier Bl. 242, Aktennotiz der Abt. I b vom 21. 6. 1948.

190 ZVBl. 1948, S. 255-258.

191 Das läßt sich aus einem Aktenvermerk über eine Besprechung in Karlshorst am 19.7. 1948 schlieBen. Vgl. BAB, DQ 2/2040, Bl. $154 \mathrm{f}$. Diese Arbeiten waren auch im August noch nicht abgeschlossen. Vgl. BAB, DQ 2/1950, Bericht über Besprechung mit der SMAD am 3. 8. 1948, S. 2. 
Bei der Auslegung der neuen Verordnung ergaben sich rasch Meinungsverschiedenheiten zwischen der HVAS und einzelnen Landesregierungen. So hatte etwa das Ministerium für Arbeit und Sozialpolitik in Sachsen-Anhalt darauf hingewiesen, daß die Frage der Beteiligung des Arbeitsamtes bei Entlassungen nicht angesprochen worden sei. Deshalb müsse in dieser Frage nach wie vor der Kontrollratsbefehl Nr. 3 und die Dienstanweisung vom 16. Mai 1947 herangezogen werden. Demzufolge war - so das Landesministerium weiter - bei der Entlassung die Genehmigung durch das Arbeitsamt nicht erforderlich, das allerdings ein Widerspruchsrecht besitze ${ }^{192}$. Die Hauptabteilung 3 des FDGB-Bundesvorstandes war von seinem Landesverband in Sachsen-Anhalt darüber informiert worden und kritisierte diese Interpretation heftig: Die Frage der Mitwirkung des Arbeitsamtes bei Entlassungen habe mit der gerade in Kraft getretenen Verordnung „doch überhaupt nichts zu tun“"193. Dem zuständigen Mitarbeiter des Ministeriums in Halle wurde vorgeworfen, die Verordnung ,in einem von ihm gewünschten Sinne zu verbiegen. "Der FDGB-Bundesvorstand wies den Landesvorstand in Halle an, bei zukünftigen Besprechungen „derartige Absichten [...] künftig von vornherein mit dem nötigen Nachdruck [zu] zerschlagen." Sehr viel grundsätzlicher erschien dagegen die Auseinandersetzung mit dem thüringischen Ministerium für Arbeit und Sozialwesen, das für eine striktere Eingrenzung der Arbeitseinweisungen eintrat und in dem Zusammenhang auf einige Unstimmigkeiten in der Verordnung aufmerksam machte ${ }^{194}$. Die HVAS verteidigte die maßgeblich unter ihrer Federführung erarbeitete Verordnung, machte aber auch deutlich, daß an einzelnen Stellen der Wortlaut zu Mißverständnissen Anlaß geben kann ${ }^{195}$. Ein merkwürdiges Rechtsverständnis offenbarte der HVAS-Präsident mit der Bemerkung, daß „,bei strittiger Auslegung nicht nur der Wortlaut der Verordnung, sondern auch der Wille des Gesetzgebers zur Auslegung herangezogen" werden müsse. Einzelfragen sollten nach den Vorstellungen Bracks in einer eigenen Durchführungsverordnung geklärt werden. Zu den noch offenen Fragen gehörte auch die Einteilung von Betrieben in eine der drei Dringlichkeitsstufen. Hierzu mußten die Landesregierungen Listen erstellen, die dann der HVAS unterbreitet wurden ${ }^{196}$.

Zu diesem Zeitpunkt arbeitete bereits die Hauptabteilung I (Arbeitskraftplanung) der HVAS an einer entsprechenden Dienstanweisung. Der dritte Entwurf vom 28. September 1948 verdeutlichte nochmals die Problemzonen, die es zu regeln galt ${ }^{197}$. Das betraf in erster Linie die Durchführung der Einstufung, die vom jeweiligen Arbeitsamt vorgenommen werden sollte. Das Landesamt für Arbeit und Sozialfürsorge hatte dies zu prüfen und zu genehmigen. Die grundsätzliche

192 SAPMO, DY 34, 18/e/331, Aktenvermerk des Ministeriums für Arbeit und Sozialpolitik vom 14.7. 1948.

${ }^{193}$ Ebenda, FDGB-Bundesvorstand (HA 3) am 1.9. 1948 an den FDGB-Landesvorstand SachsenAnhalt (HA 3).

194 ThHStA, Land Thüringen, Ministerium für Wirtschaft und Arbeit, Bd. 3695, Bl. 133f., Briefentwurf des thüringischen Ministeriums für Arbeit und Sozialwesen vom 17.8. 1948 an die HVAS.

195 Ebenda, Bl. 135, HVAS-Präsident Brack am 6. 9. 1948 an das Ministerium für Arbeit und Sozialwesen in Erfurt.

196 Vgl. etwa ebenda, Bl. 141, Ministerium für Wirtschaft des Landes Thüringen (HA Industrie und Brennstoff) am 21.9. 1948 an das Ministerium für Arbeit und Sozialwesen in Erfurt.

197 BAB, DQ 2/2047. 
Schwierigkeit bei diesem Einstufungsverfahren wurde explizit an der Bestimmung erkennbar, wonach ein Betrieb in verschiedene Dringlichkeitsstufen eingeordnet werden konnte, „wenn es nach der Art seiner Produktion erforderlich ist.“ Darüber hinaus versuchte der Entwurf die Durchführung der Arbeitsvermittlung festzulegen, die in den Händen der Arbeitsämter lag und auch das Recht zum überbezirklichen Ausgleich von Arbeitskräften beinhaltete. Die SMAD genehmigte die Dienstanweisung Nr. 1 noch Anfang Oktober ${ }^{198}$. Daneben erstellte die HVAS eine Durchführungsbestimmung, welche die Errichtung der Beschwerdeausschüsse sowie das Beschwerdeverfahren regeln sollte und die am 22. Oktober 1948 von der DWK veröffentlicht wurde ${ }^{199}$.

Die Umsetzung der Verordnung erfolgte oftmals nicht reibungslos. Vor allem bei den festgesetzten Trennungsgeldern, die bei einer Arbeitseinweisung auszuzahlen waren, zeigten sich die unterschiedlichen Positionen von der HVAS auf der einen und den Betrieben auf der anderen Seite, welche die finanzielle Belastung nicht ohne weiteres zu übernehmen bereit waren. An ihre Grenzen stieß jedoch die HVAS bei den SAG: Hier stellten im Sommer 1949 einige SAG-Betriebe die Zahlung von Trennungsentschädigung unter fadenscheiniger Begründung ein ${ }^{200}$. Daraufhin wandte sich die Berliner Hauptverwaltung direkt an die SMAD-Abteilung Arbeitskraft und machte auf die negativen Folgen für die Freiwilligenwerbung aufmerksam: „Wenn die SAG-Betriebe die Zahlung von Trennungsgeld einstellen, so wird es uns in Zukunft kaum möglich sein, die zur Erfüllung ihrer Produktionsauflagen erforderlichen Arbeitskräfte, vor allem Spezialkräfte, auf freiwilliger Basis zu vermitteln, sofern sie nicht auf dem örtlichen Arbeitsmarkt zur Verfügung stehen."201 Die SMAD-Abteilung wurde gebeten, die Generaldirektion der SAG-Betriebe in Berlin-Weißensee auf diese Konsequenzen hinzuweisen. Letztlich hatte die HVAS jedoch keinerlei Druckmittel in der Hand, um ihren Standpunkt in dieser Frage gegenüber der sowjetischen Besatzungsmacht durchsetzen zu können. Schließlich stimmte die HVAS sogar der Abfassung von Arbeitsverträgen zwischen den SAG-Betrieben und einzelnen Beschäftigten zu, in denen der Anspruch auf Trennungsentschädigung ausdrücklich ausgeschlossen wurde 202 .

\section{Aufbau der Arbeitsgerichte}

Arbeitsrechtliche Auseinandersetzungen zwischen Arbeitgebern und Arbeitnehmern werden in modernen Industriegesellschaften vor Arbeitsgerichten ausgetragen. Nach dem Zusammenbruch 1945 mußte in der SBZ diese arbeitsrechtliche Schiedsstelle neu konzipiert und aufgebaut werden. Inhaltlich gab es zunächst einige Anknüpfungspunkte zur Weimarer Republik. Gleichzeitig war das Ziel einer strukturellen Veränderung unübersehbar: In der SBZ sollte die organisatorisch

198 Das geht aus der Niederschrift über den Verlauf der Arbeitstagung der HVAS in Bad Kösen am 5./6. 10. 1948 (S. 11) hervor, in: BAB, DQ 2/1762.

199 Sowohl die Dienstanweisung Nr. 1 als auch die Durchführungsbestimmungen sind abgedruckt in: Arbeit und Sozialfürsorge 3 (1948), S. 449-451.

$200 \mathrm{Vgl}$. BAB, DQ 2/2063, Aktenvermerk der HVAS-Abt. I a vom 28. 6. 1949.

201 BAB, DQ 2/2076, HVAS am 21.6. 1949 an Morenow.

$202 \mathrm{BAB}, \mathrm{DQ} 2 / 2063$, Aktenvermerk der HVAS-Abt. I a vom 28. 6. 1949. 
enge Verbindung der Arbeitsgerichte mit der ordentlichen Gerichtsbarkeit aufgelöst werden. Darin bestand die große Verbesserung gegenüber Weimar; eine ähnliche Entwicklung ist übrigens auch für die westlichen Besatzungszonen bzw. die frühe Bundesrepublik zu beobachten ${ }^{203}$. In der DDR wurde 1953 eine neue, konkurrierende Einrichtung geschaffen: die Konfliktkommission. Dadurch wurde der Interessengegensatz, der nach Ansicht der SED-Führung zwischen Arbeitnehmern und Betriebsleitern nicht mehr bestand, der arbeitsrechtlichen Ebene entzogen und weitgehend der betrieblichen zugeführt ${ }^{204}$. Daneben hatten zwar die Arbeitsgerichte nach wie vor Bestand, ihre Bedeutung sollte aber sukzessive abnehmen.

Beim Aufbau der Arbeitsgerichte schien in der SBZ eine rasche und einheitliche Lösung geboten zu sein. Da die ZVAS Ende 1945 über keine Weisungsbefugnisse verfügte, drohte die Entwicklung in den einzelnen Ländern und Provinzen auseinanderzudriften, zumal der Bedarf an Arbeitsgerichten offenkundig war. So meldete etwa der Berliner Magistrat am 23. Oktober 1945, daß bei den Amtsgerichten "die ersten gerichtlichen Austragungen von Arbeitsstreitigkeiten [laufen] "205. Vorschläge von seiten des FDGB gingen wohl dahin, zunächst einmal eine provisorische Regelung zu treffen und durch eine Vollzugsanweisung das Arbeitsgerichtsgesetz vom 23. Dezember 1926 in der Fassung vom 10. April 1934 sowie vom 30. März 1935 in Kraft zu setzen ${ }^{206}$. Dabei hätten allerdings einige Änderungen, die nach der nationalsozialistischen Machtergreifung vorgenommen worden waren, wieder rückgängig gemacht werden müssen: die Übertragung bestimmter Rechte auf die Treuhänder der Arbeit, die Einbeziehung der Deutschen Arbeitsfront (DAF) und die Zulassung von Anwälten als Prozeßbeauftragte.

Erste Anregungen zum Neuaufbau der Arbeitsgerichtsbarkeit in der SBZ kamen offensichtlich aus Berlin. Die Tatsache, daß die Nationalsozialisten wichtige Bestandteile der Arbeitsgerichtsbarkeit aus der Weimarer Republik mit übernommen und anschließend verändert hatten, war ein zusätzlicher Beweggrund für zahlreiche KPD-Politiker nach 1945, eine grundsätzliche Neuordnung vorzunehmen. So wurde etwa betont, daß bei einer „Demokratisierung“ des Arbeitsrechts "keineswegs" auf das Weimarer Gesetz von 1926 zurückgegriffen werden könne 207 . Die "Herstellung demokratischer Verhältnisse" verlange daher die Schaffung eines Arbeitsgerichtsgesetzes, „auf der Grundlage der Trennung von den ordentlichen Gerichten und der Bestellung von Vorsitzenden, die mit den betrieblichen Verhältnissen vertraut sind." Der KPD ging es frühzeitig um eine partielle Herauslösung der Arbeitsgerichtsbarkeit aus der traditionellen Rechtsprechung: Deren Aufgabe sei es vielmehr, „durch eine betriebsnahe und demo-

${ }^{203}$ Vgl. zur Sozial- und Arbeitsgerichtsbarkeit in der frühen Bundesrepublik: Hockerts, Sozialpolitische Entscheidungen, S. 160-165.

204 Vgl. zu den Konfliktkommissionen: Frerich/Frey, Sozialpolitik in der DDR, S. 123-125; Hachtmann, Arbeitsverfassung, S. 45; Mampel, Beiträge zum Arbeitsrecht, S. 86-129.

205 SAPMO, NY 4182/1158, Bl. 79, Hans Jendretzky an Walter Ulbricht.

206 Vgl. ebenda. Vgl. zur Arbeitsgerichtsbarkeit in der Weimarer Republik: Bähr, Entstehung und Folgen des Arbeitsgerichtsgesetzes; Preller, Sozialpolitik in der Weimarer Republik, S. 341-345; Ritter, Der Sozialstaat, S. $124 \mathrm{f}$.

207 SAPMO, NY 4182/1158, Bl. 81-84, hier Bl. 83, Denkschrift vermutlich vom Magistrat der Stadt Berlin (o. D.). 
kratischen Auffassungen entsprechende Rechtsprechung an der Demokratisierung des betrieblichen Lebens und damit an der Schaffung eines neuen demokratischen Deutschlands mitzuwirken" 208 .

Einer der ersten Entwürfe für ein Arbeitsgerichtsgesetz stammte vermutlich ebenfalls vom Berliner Magistrat ${ }^{209}$, der explizit eine gegensätzliche Position zum nationalsozialistischen Arbeitsrecht bezog und dies bereits in der Präambel sehr deutlich machte. Der Aufbau der Arbeitsgerichte wurde als Aufgabe der Selbstverwaltungsorgane in den Gemeinden und Provinzen bzw. Ländern bezeichnet; eine vergleichbare Entwicklung war auch beim Aufbau der Arbeitsverwaltung zu beobachten gewesen. Die Errichtung sollte ebenso auf drei unterschiedlichen Ebenen erfolgen: Arbeitsgerichte bei den Kommunen, den Landesverwaltungen sowie bei der ZVAS. Gleichzeitig war jedoch eine Unterordnung bei der zuständigen Abteilung für Arbeit vorgesehen ${ }^{210}$. Der Entwurf legte insgesamt die personelle Zusammensetzung der Gerichte und das Verfahren selbst fest. Demzufolge waren bei den einzelnen Arbeitsgerichten eine oder mehrere Kammern zu bilden, die sich aus jeweils einem Vorsitzenden und zwei Beisitzern zusammensetzten und von der zuständigen Abteilung für Arbeit bestellt werden mußten. Bei den Beisitzern sollte je ein Vertreter von seiten der Gewerkschaften sowie der Unternehmer ernannt werden. Alle Kammermitglieder, die nur für ein Jahr ernannt wurden - eine erneute Bestellung war durchaus möglich - , sollten ,arbeitsrechtliche und sozialpolitische Kenntnisse“ besitzen und mit „dem Betriebsleben vertraut" sein. Die Berufung von Berufsrichtern oder Rechtsanwälten als Vorsitzende oder Beisitzer wurde ausdrücklich ausgeschlossen. Somit spielte die berufliche Qualifikation eine geringere Rolle als das Bekenntnis zur neuen politischen Ordnung: „Sie müssen eine antifaschistische, demokratische Lebensauffassung besitzen. "211 Funktionäre der NSDAP sowie der nationalsozialistischen Organisationen wurden von der Mitwirkung explizit ausgeschlossen. Die Zuständigkeit der Arbeitsgerichte erstreckte sich auf individuelle Streitfälle, die den Arbeitsvertrag, die Lohnregelung, die Betriebsordnung, die tariflichen Vereinbarungen und den Lehrvertrag betrafen.

In der Folgezeit wurde die Vorstellung von der Abkoppelung der Arbeitsgerichte von den ordentlichen Justizbehörden und der Anbindung an die allgemeinen Arbeitsverwaltungsbehörden immer drängender vorgebracht ${ }^{212}$. Der FDGBBundesvorstand plädierte für die Bildung von zwei Kammern innerhalb der Arbeitsgerichte: jeweils für arbeits- und für sozialrechtliche Angelegenheiten ${ }^{213}$. Anfang 1946 bestanden noch keine eigenständigen Arbeitsgerichte in der SBZ; diese waren vielmehr ,im Rahmen der allgemeinen Justiz tätig"214. Der stellvertretende Chef der SMAD-Abteilung Arbeitskraft P. J. Morenow verwies bei einer

208 Ebenda, Bl. $83 \mathrm{f}$.

209 SAPMO, NY 4182/1158, Bl. 85-94, Entwurf (o. Verf.; o. D.). Aus dem Aktenzusammenhang ergibt sich, daß als Urheber nur der Magistrat der Stadt Berlin in Frage kommen kann.

210 Ebenda, Bl. 86.

211 Ebenda, Bl. 87.

212 SAPMO, NY 4182/1180, Bl. 57-59, Notiz vom 6. 12. 1945.

213 SAPMO, NY 4182/1158, Bl. 98-101, Vorschlag des FDGB (o. D.).

214 BAB, DQ 2/797, Bericht über die Besprechung mit Vertretern des Landesamtes für Arbeit und Sozialfürsorge in Dresden am 15./16. 1. 1946, S. 5. 
Besprechung am 23. Januar auf die laufenden Verhandlungen im Alliierten Kontrollrat und betonte, daß eine Einigung über die Grundsätze, „wie sie von der Zentralverwaltung ausgearbeitet wurden", bereits erreicht worden sei ${ }^{215}$. Die SMAD kam allerdings einer Regelung für alle vier Besatzungszonen zuvor und veröffentlichte am 25. Januar eine Verordnung über Arbeitsgerichte in der SBZ216. Dabei wurden die Arbeitsgerichte als Gerichte erster und zweiter Instanz errichtet und den Ämtern für Arbeit bei den Landes- und Provinzialverwaltungen unterstellt, welche die arbeitsrechtlichen Entscheidungen allerdings nicht aufheben konnten. Neu war die Einführung der beruflichen Qualifikation als Voraussetzung zur Ernennung des Vorsitzenden in der zweiten Instanz. Inhaltlich ergaben sich keine größeren Unterschiede zum Gesetz Nr. 21 des Alliierten Kontrollrates, das etwa zwei Monate später, nämlich am 30. März 1946 vorlag217. Sowohl der SMAD-Befehl als auch das Kontrollratsgesetz nahmen Bezug auf das Weimarer Gesetzeswerk von 1926, das weiterhin in Kraft blieb, sofern es in einzelnen Bestimmungen den neuen Gesetzestexten nicht widersprach. Damit war die gesetzliche Grundlage für die Arbeitsgerichtsbarkeit in der SBZ gelegt.

Während die Ausarbeitung des SMAD-Befehls in enger Zusammenarbeit mit der ZVAS, aber auch mit dem FDGB-Bundesvorstand erfolgte, trat das ZK der $\mathrm{KPD}$ vor allem bei der personellen Besetzung der neuen Gerichte in Erscheinung. So wurden die KPD-Bezirksleitungen am 20. Februar 1946 angewiesen, sich über den weiteren Verlauf zu informieren und diesen zu beeinflussen: „Greift mit dem FDGB überall ein, wo es notwendig ist. " Die Zielrichtung lieferte das Sekretariat des ZK der KPD unmißverständlich mit: „Je mehr Genossen und bewährte Antifaschisten in diese Ämter eingesetzt werden, umso mehr besteht die Gewißheit, daß die Arbeitsgerichte nicht wieder reaktionäre Urteile fällen, wie in der Weimarer Republik, sondern Arbeitstribunale werden, die im antifaschistischen demokratischen Deutschland nicht zu Klagen Anlaß geben. "218 Da die Errichtung der Arbeitsgerichte nicht in dem Maße voranschritt, wie sich das ZVAS, FDGB und KPD ursprünglich erhofft hatten, wurde bei der Berliner Zentralverwaltung über den Aufbau von sogenannten Spruchausschüssen bei den Ämtern für Arbeit und Sozialfürsorge zur Entlastung der bereits bestehenden Arbeitsgerichte nachgedacht ${ }^{219}$. Dieser Plan wurde jedoch nicht realisiert; statt dessen konzentrierte sich die Berliner Zentralverwaltung auf die rasche Umsetzung der KPD-Anweisungen.

Die DVAS verfolgte aufmerksam den weiteren personellen Aufbau und die inhaltliche Tätigkeit der Arbeitsgerichte in den Ländern und Provinzen. Zu diesem Zweck unternahm die zuständige Juristische Abteilung gezielt Dienstreisen. Am 1. März 1946 bestanden in Thüringen 17 Arbeitsgerichte sowie ein Landesarbeitsgericht mit Sitz in Erfurt; Sachsen verfügte zu diesem Zeitpunkt über 25 Arbeits-

215 BAB, DQ 2/1, Bl. 31.

216 SMAD-Befehl Nr. 23 vom 25. 1.1946 mit Anlage und Richtlinien, in: Arbeit und Sozialfürsorge 1 (1946), S. 14-18.

217 Amtsblatt des Kontrollrats in Deutschland, S. 124-127.

218 Dokumente zur Geschichte der kommunistischen Bewegung in Deutschland, Bd. 3, S. 443.

${ }^{219} \mathrm{BAB}, \mathrm{DQ} 2 / 1738$, Notiz der Abt. II vom 26. 2. 1946, S. 4-8. 
gerichte und ein Landesarbeitsgericht mit Sitz in Dresden 220. Die parteipolitische Bindung der Vorsitzenden war eindeutig zugunsten der Arbeiterparteien: In Thüringen wurden acht Vorsitzende der SPD, vier der KPD und einer der CDU zugeordnet, vier waren parteilos 221 ; für Sachsen lag eine vergleichbare Übersicht nicht vor. In Brandenburg besaßen alle Vorsitzenden der insgesamt 27 Arbeitsgerichte das SED-Parteibuch; auch der Leiter des Berufungsgerichtes in Potsdam gehörte der SED an ${ }^{222}$. Auffallend war, daß keiner der Arbeitsgerichtsvorsitzenden eine juristische Ausbildung vorzuweisen hatte; nur der Vorsitzende beim Berufungsgericht war ausgebildeter Jurist. Dies entsprach aber insgesamt den gesetzlichen Bestimmungen von seiten des Alliierten Kontrollrates und der SMAD. Die brandenburgische Provinzialverwaltung schätzte die Tätigkeit der Arbeitsgerichte insgesamt sehr positiv ein und sorgte in Form von monatlichen Besprechungen mit allen Vorsitzenden für einen relativ engen Informationsaustausch ${ }^{223}$. Auch die Angaben der mecklenburgischen Landesverwaltung 224 bestätigen den allgemeinen Trend: In der Regel waren die Vorsitzenden der Arbeitsgerichte keine Juristen; einzige Ausnahme war die übergeordnete Instanz. Darüber hinaus ist der dominierende Einfluß der SED in diesem Bereich nochmals zu unterstreichen. Im Spätsommer 1946 war der Aufbau der Arbeitsgerichte in den Ländern und Provinzen abgeschlossen. Insgesamt bestanden 110 Arbeitsgerichte: Sachsen (25), Thüringen (17), Mecklenburg-Vorpommern (21), Sachsen-Anhalt (20) und Brandenburg (27) 225 .

Auf der 1. Konferenz der Vorsitzenden der Berufungsarbeitsgerichte mit den Leitern der Landesämter für Arbeit und Sozialfürsorge am 6. August 1946 machte der Leiter der Juristischen Abteilung der DVAS, Rudolf Helm, die gewandelte Funktion der Arbeitsgerichtsbarkeit in der SBZ deutlich, die sich trotz diverser Anknüpfungspunkte doch erheblich von der Situation während der Weimarer Republik unterscheiden sollte. Die "neuen“ Arbeitsrichter sollten - so Helm in seinem Vortrag - „keine Formaljuristen sein und werden, keine Formalisten und Doktrinäre, sondern über Streitigkeiten aus dem Arbeits- und Sozialleben unverbildet [sic], lebensnahe, mit ihrem gesunden Menschenverstand entscheiden" ${ }^{226}$. Sie seien Männer der „werktätigen“ Bevölkerung, mit dem Berufsleben vertraut und vor allem unbelastet von den "gelehrten, spitzfindigen, jetzt so sehr anfechtbaren Entscheidungen des höchsten Gerichts der Weimarer Republik und des Hitler-Staates." Entscheidend für die Berufung der Arbeitsrichter war auch hier nicht so sehr die fachliche Qualifikation, sondern die „antifaschistische Gesinnung [und] klare demokratische Haltung." Im Zuge der als "Demokratisierung“ bezeichneten Umwälzungen in der Wirtschaft (in erster Linie waren damit Sequestrierung und Verstaatlichung gemeint) wurde den Arbeitsgerichten eine „ent-

${ }^{220} \mathrm{BAB}, \mathrm{DQ} 2 / 1237$, Bericht der DVAS (Juristische Abt.) vom 18.4. 1946 über eine Dienstreise (6.-17.4. 1946).

221 Ebenda, S. 1.

${ }_{222} \mathrm{BAB}, \mathrm{DQ} 2 / 89, \mathrm{Bl} .2-9$, Bericht aus der brandenburgischen Landesverwaltung vom 16. 9. 1946.

${ }^{223}$ Ebenda, Bl. 9.

${ }_{224} \mathrm{BAB}, \mathrm{DQ} 2 / 89$, Bl. 11-14, Bericht, vermutlich von der Landesregierung Mecklenburg-Vorpommern vom Spätsommer 1946.

$225 \mathrm{BAB}, \mathrm{DQ} 2 / 88, \mathrm{Bl}$. 3, Juristische Abt. der DVAS am 24. 9. 1946.

$226 \mathrm{BAB}, \mathrm{DQ} 2 / 273$, Vortrag Helms, S. 4. 
scheidende Rolle“227 zugesprochen. Sie hatten diesen Prozeß nach den Vorstellungen der DVAS-Leitung zu fördern und zu unterstützen.

Die SMAD nahm vermutlich keinen direkten Einfluß auf die Errichtung der Arbeitsgerichtsbarkeit der SBZ, ließ sich aber von der DVAS in unregelmäßigen Abständen über die Tätigkeit derselben berichten. Gegenüber der Abteilung Arbeitskraft machte die DVAS-Leitung detaillierte Angaben über die Gesamtzahl der Streitfälle in den einzelnen Ländern bzw. Provinzen sowie über einzelne arbeitsrechtliche Bereiche. Die mit Abstand meisten Streitfälle wurden in Sachsen registriert: Hier lagen bis zum 30. November 1946 in erster Instanz 3142 Fälle vor; davon waren noch 986 unerledigt. Dabei trafen die dortigen Arbeitsgerichte 967 Entscheidungen zu Lohnfragen, 503 betrafen Entlassungen und 30 tangierten Urlaubsfragen 228. In zweiter Instanz gab es 119 Streitfälle, von denen 25 noch nicht abschließend geregelt werden konnte; auch hier zeigte sich eine ähnliche Verteilung auf die jeweiligen arbeitsrechtlichen Gebiete. Die geringste Anzahl an Streitfällen hatte die Landesverwaltung von Mecklenburg-Vorpommern gemeldet: Hier wurden 832 Streitfälle registriert, von denen 171 noch nicht abgeschlossen worden waren. Die Anzahl der Entscheidungen betraf auch hier mehrheitlich Lohnfragen (371), gefolgt von 151 Entlassungsfällen sowie sechs Entscheidungen zu Urlaubsfragen ${ }^{29}$. Aufschlußreich für die Einschätzung der Tätigkeit der Arbeitsgerichte wäre eine statistische Erfassung der Entscheidungen zugunsten der Arbeitnehmer bzw. der Arbeitgeber gewesen; diese lag der DVAS jedoch zu diesem Zeitpunkt nicht vor. Eine Gegenüberstellung existiert dagegen für das 1. Halbjahr 1948: Hier wurden 2294 Entscheidungen zugunsten der Arbeitnehmer und 1337 zugunsten der Unternehmer getroffen. Das Zahlenverhältnis verbesserte sich aus Arbeitnehmersicht nochmals im 1. Halbjahr 1949: 3855 Urteilen zugunsten der Arbeitnehmer standen 1949 zugunsten der Arbeitgeber gegenüber ${ }^{230}$.

Fragen des Arbeitsrechts spielten auch auf der Juristenkonferenz am 1./2. März 1947 eine zentrale Rolle, da Helm erneut den funktionalen Charakter der Arbeitsgerichte in der sich wandelnden Wirtschaftsordnung ansprach. Er stellte die gesetzliche Fundierung der Arbeitsgerichtsbarkeit in der SBZ in eine Reihe mit dem Betriebsrätegesetz und dem Schlichtungsgesetz. Dies seien - so der Leiter der Juristischen Abteilung - Rahmengesetze, die "dem wirtschaftlichen, insbesondere dem gewerkschaftlichen Kampf zur Entfaltung aller demokratischen Kräfte den erforderlichen Spielraum geben" 231 . Daher sollten "nur die absolut reifen Fragen in Gesetzesform gekleidet werden [...], um eine Erstarrung zu vermeiden". Letztlich ging es der DVAS darum, den eigenen Handlungsspielraum durch arbeitsrechtliche Bestimmungen nicht zu sehr einzuengen. Der Gestaltungsspielraum und die Flexibilität staatlichen Handelns sollten gewahrt bleiben. Maßgeblich war aus Sicht der DVAS-Leitung aber auch der SED-Führung der wirtschaftliche Auf-

${ }^{227}$ Ebenda, S. 10.

${ }^{228} \mathrm{BAB}, \mathrm{DQ} 2 / 81, \mathrm{Bl} .360$, Statistische Unterlagen der Arbeitsgerichte im Land Sachsen. Es blieb eine Restgröße von 656 Entscheidungen, die nicht weiter eingruppiert wurden.

${ }_{229}$ Ebenda, Bl. 358, Statistische Unterlagen der Arbeitsgerichte im Land Mecklenburg-Vorpommern. Auch hier tauchte in der Statistik ein Restgröße von 133 Entscheidungen auf, die nicht eindeutig zugeordnet waren.

230 Frerich/Frey, Sozialpolitik in der DDR, S. 54.

$231 \mathrm{BAB}, \mathrm{DQ} 2 / 273$, Referat Helms, S. 3. 
bau nach den Vorstellungen der Hegemonialpartei; diesem Ziel wurden andere Projekte untergeordnet. Interessant war Helms Vorstoß, Arbeitsrecht in den Unterrichtsplan der Volksrichterausbildung aufzunehmen. Dies müsse „als eines der Kernprobleme bei der Demokratisierung der Justiz und der Wirtschaft mit behandelt werden" 232 . Damit sollte offensichtlich langfristig gewährleistet bleiben, daß die Vorsitzenden der Berufungsgerichte, die laut Verordnung Juristen sein mußten, ebenfalls im Sinne der SED- und DVAS-Führung arbeitsrechtliche Entscheidungen treffen. In der Rundverfügung des Chefs der Deutschen Zentralverwaltung für Justiz an die Landesregierungen am 8. September 1947, welche die Lehrpläne der Volksrichterlehrgänge beinhaltete, wurde auch das Arbeitsrecht mit geringer Stundenzahl im Vorlesungsplan berücksichtigt ${ }^{233}$.

Aus Sicht der Arbeitsverwaltung entwickelten sich die Arbeitsgerichte in zunehmendem Maße zu einem Bremsfaktor bei der Arbeitskräftelenkung, vor allem bei der Arbeitseinweisung. Gegen dieses Zwangsinstrument konnten die Betroffenen durchaus Einspruch anmelden, der jedoch keine aufschiebende Wirkung hatte. Neben den Beschwerdekommissionen wurden nunmehr auch die Arbeitsgerichte mit Einzelklagen überhäuft. Neben der DVAS-Leitung beklagte auch die SMAD-Abteilung Arbeitskraft, daß die Beschwerdeausschüsse „nicht den Erfordernissen der Arbeitslenkung entsprechen und sich in der Praxis überdies als undurchführbar" erwiesen hätten ${ }^{234}$. Im einzelnen wurde moniert, daß die Anzahl der eingereichten Beschwerden gar nicht zu bewältigen sei. Darüber hinaus bestünde die Gefahr des Autoritätsverlustes der Arbeitsamtsleiter, da ihre Entscheidungen "dauernd umgeworfen werden könnten." Als weitere Folgewirkung nannten die SMAD-Vertreter außerdem, daß die Leiter der Arbeitsämter vor dem Hintergrund der Erfahrungen, die sie mit den Beschwerdeausschüssen gemacht hätten, vor unpopulären Entscheidungen zurückschrecken würden. Dadurch wäre aber die Erfüllung der sowjetischen Arbeitskräfteanforderungen gefährdet. SMAD und DVAS einigten sich darauf, daß eine frühzeitige Absprache mit den Beratungsausschüssen zu suchen sei. Letztlich hätten aber die Arbeitsämter bzw. Landesarbeitsämter die Verantwortung alleine zu tragen, und daher müßten ihre Beschlüsse auch bindenden Charakter haben. Die Einwände trafen nach Ansicht der Tagungsteilnehmer in Rostock „im verstärkten Maße“ auf die Arbeitsgerichte $\mathrm{zu}^{235}$. Die Juristische Abteilung der DVAS kritisierte in dem Zusammenhang die Arbeitsgerichte und warf diesen vor, ihren Zuständigkeitsbereich verlassen zu haben. Einige Gerichte hätten den Versuch unternommen, Arbeitseinweisungen individuell zu überprüfen und „in verschiedenen Fällen als ungesetzlich“ zu bezeichnen. Vertreter der Landesverwaltungen äußerten daraufhin den Wunsch, daß dieser Standpunkt „in einer offiziellen Form zur allgemeinen Kenntnis gelangen solle."

Die Arbeitsgerichtsbarkeit blieb auch weiterhin ein Thema bei den Treffen der Landesarbeitsminister mit der DVAS-Leitung. Dabei betonte im Oktober 1947

232 Ebenda, S. 6.

233 Volksrichter in der SBZ/DDR, S. 191

${ }_{234} \mathrm{BAB}, \mathrm{DQ} 2 / 111, \mathrm{Bl} .53 \mathrm{f}$., Aktenvermerk über Tagung der Abt. Arbeitslenkung in Rostock am 19./20. 8. 1947.

235 Ebenda, Bl. 54. 
ein Mitarbeiter der Berliner Zentralverwaltung, Schaum, die Notwendigkeit, Ausbildung und Unterbringung der Arbeitsrichter weiter zu verbessern ${ }^{236}$. Im einzelnen wurde beanstandet, $\mathrm{da} ß$ die Arbeitsgerichte räumlich gesehen bei den Ämtern für Arbeit und Sozialfürsorge, den Amtsgerichten oder beim FDGB untergebracht waren. Die Unterbringung müsse - so Schaum - „mehr der Würde derselben entsprechen " ${ }^{237}$. Fragen der Besoldung und Amtsbezeichnung wurden in der Regel von einer Geschäftsordnung geregelt, die zu diesem Zeitpunkt offensichtlich noch nicht vorgelegen hatte. Im Sommer 1948 war außerdem das Verfahren vor den Arbeitsgerichten noch nicht restlos geklärt, was die Unsicherheit etwa auf seiten der Arbeitsämter erhöhte. Diese mußten in Einzelfällen entscheiden, ob Arbeitskräfte, die sich in einem schwebenden Arbeitsgerichtsprozeß befanden, in eine andere Arbeit eingewiesen werden konnten, und wandten sich hilfesuchend an das zuständige Landesministerium ${ }^{238}$. Ungefähr zu diesem Zeitpunkt setzte auch ein Bedeutungsverlust der Arbeitsgerichte in der SBZ ein, der sich bis zur DDR-Gründung fortsetzen sollte. So wurden Anfang 1949 Polizeiangestellte der ordentlichen Arbeitsgerichtsbarkeit entzogen ${ }^{239}$.

$236 \mathrm{BAB}, \mathrm{DQ} 2 / 1891, \mathrm{Bl}$. 23-32, Bericht über die Konferenz der Landesarbeitsminister am 20./21. 10. 1947 in Berlin.

237 Ebenda, Bl. 30.

238 ThHStA, Land Thüringen, Ministerium für Wirtschaft und Arbeit, Bd. 3695, Bl. 143, Amt für Arbeit und Sozialfürsorge Gera am 28. 6. 1948 an das Ministerium für Arbeit und Sozialwesen in Erfurt.

${ }^{239}$ SAPMO, DY 30/IV 2/2.027/5, Bl. 285, Bericht über die Besprechung Lehmanns mit Brack, Matern und Litke am 1.4. 1949. 